\title{
LA REPERCUSIÓN DE LA RESPONSABILIDAD POR INCUMPLIMIENTO DEL DERECHO DE LA UNIÓN EUROPEA EN EL CONTEXTO DEL ESTADO AUTONÓMICO*
}

\author{
ISAAC MaRTín Delgado \\ Profesor titular de Derecho Administrativo \\ Director del Centro de Estudios Europeos «Luis Ortega Álvarez» \\ Universidad de Castilla-La Mancha
}

\section{RESUMEN}

EI legislador español ha procedido a regular y el Gobierno a desarrollar la re percusión de la responsabilidad económica derivada de incumplimientos del Derecho de la Unión Europea por acciones u omisiones imputables a comunidades autónomas. Sin embargo, lo ha hecho desde una visión eminentemente estatalista, situando a las Administraciones autonómicas en la posición de simples administrados. En este trabajo se analiza exhaustivamente la citada normativa y se ponen de manifiesto las anomalías existentes en los primeros casos de aplicación, planteando posi bles soluciones para normalizar las relaciones entre el Estado central y las comunidades autónomas en este ámbito.

Palabras clave: incumplimiento del Derecho de la Unión Europea; responsabilidad; comunidades autónomas.

\begin{abstract}
The Spanish Parliament has regulated and the Government has implemented the possibility of allocating to the Autonomous Communities the financial liability - derived from infringements of E uropean Union Law-, assumed by the Central State in application of the Treaties. Nevertheless, the approach of these norms is favourable to the Central State, whereas the regional Administrations are treated as a simple party in the administrative procedure. This study analyses the new regulation and its main problematic aspects and anomalies, pointing out some solutions to them in order to normalise the relationships between the Central State and the Autonomous Communities in relation to the application of EU Law.
\end{abstract}

Key words: infringement of European Union Law; liability; autonomous communities.

\footnotetext{
* El presente artículo tiene su origen remoto en la conferencia impartida el 23 de mayo de 2014 en Granada, en el Congreso «La última evolución del Estado Autonómico en el contexto europeo», dirigido por el profesor Francisco Balaguer. Con él doy cumplimiento —si bien, más tarde de lo que hubiera sido deseable_ a la petición de mi Maestro, el Catedrático de Derecho Administrativo y Magistrado del Tribunal Constitucional Luis Ortega Álvarez, de publicar la intervención. Incorpora las novedades normativas, jurisprudenciales y administrativas producidas desde entonces, expuestas preliminarmente en la ponencia presentada en Zaragoza el pasado 5 de mayo de 2015, en el Congreso «La última evolución de la Unión Europea en el contexto global. Homenaje al Profesor y Magistrado Luis Ortega Álvarez», que dirigieron Francisco Balaguer y J osé Tudela. Sirva de reconocimiento a su excelente magisterio, a su paternidad académica y a su genial forma de entender y expresar el Derecho.
} 


\section{SUMARIO}

I. I NTRODUCCIÓN. PLANTEAMIENTO DEL TEMA.-II. INCUMPLIMIENTO DEL DERECHO DE LA UNIÓN EUROPEA, SANCIÓN Y REPERCUSIÓN: 1. Procedimiento por incumplimiento y procedimiento por inejecución. 2. La repercusión de las consecuencias económicas derivadas de incumplimiento: A) La (deficiente) regulación del mecanismo de repercusión de la responsabilidad. B) La conflictividad provocada por la regulación. 3. La aplicación del mecanismo de repercusión por el Consejo de Ministros: solución a una cuestión controvertida.-III. ALgUNAS DUDAS SIN RESOLVER: RESPONSABILIDAD CONCURRENTE Y REPERCUSIÓN A LA INVERSA: 1. La COrresponsabilidad del Estado en el contexto de incumplimientos autonómicos. A) EI Asunto Magefesa. B) EI Asunto de las vacaciones fiscales de las Diputaciones Forales vascas. 2. La posibilidad de repercutir frenteal Estado las responsabilidades económicas sufridas por las comunidades autónomas. 3. Una vía intermedia: el establecimiento de un modelo de responsabilidades fijas.-IV. ConCLUSIONES.

\section{Introducción. Planteamiento del tema}

Como es sabido, la aplicación del Derecho de la Unión Europea en nuestro sistema jurídico se rige por dos grandes principios: desdela perspectiva nacional, y como consecuencia de los principios de autonomía institucional y procedimental y de respeto a la identidad nacional de los Estados miembros reconocidos en el art. 4 TUE, por el de distribución interna de competencias de conformidad con lo establecido en la Constitución; desde la perspectiva supranacional, por el de responsabilidad internacional del Estado, único operador válido ante las instituciones europeas y, por ello, quien debe responder en caso de incumplimiento del mismo.

En Estados descentralizados como el nuestro, la aplicación de ambos princi pios lleva a la paradójica conclusión de que no responde necesariamente del incumplimiento del Derecho de la Unión Europea el responsable del mismo, sino el Estado central, aunque la competencia afectada por la normativa infringida corresponda a un ente territorial inferior.

Ello ha conducido al legislador español a incluir en nuestro ordenamiento jurídico disposiciones concretas que reconocen la responsabilidad última del autor material del incumplimiento y, en el caso de condena efectiva al Reino de España, la posibilidad de repercutir la sanción impuesta a la Administración Pública responsable.

Sin embargo, lo ha hecho fuertemente marcado por la visión del Consejo de Estado - anticipada en su Informe sobre la inserción del Derecho Europeo en el Derecho Español de 14 de febrero de 2008 y desarrollada en profundidad en el Informe de 15 de diciembre de 2010 
sobre las garantías del cumplimiento del Derecho Comunitario-, que presenta la cuestión de la repercusión como elemento nuclear en relación con las necesidades de reforma ante el problema de la inobservancia del Derecho de la Unión Europea, situándola al mismo nivel de la prevención y de la reacción frente al incumplimiento y, además, desde un prisma excesivamente centralista.

Como consecuencia de ello, la cláusula general de repercusión y el procedimiento administrativo delineado - recientemente desarrollado por el Gobierno y que ya está teniendo sus primeras aplicaciones- poseen una clara impronta estatal, descartando implícitamente toda asunción de responsabilidad parcial por parte del propio Estado y situando a los entes territoriales repercutidos en una posición de simple administrado, como se tendrá ocasión de comprobar en las siguientes páginas.

La tesis que se sostendrá en ellas puede resumirse del siguiente modo: tal y como está configurado actualmente el sistema de ejecución del Derecho de la Unión en nuestro país, con un protagonismo evidente del Estado central frente a las comunidades autónomas en el caso de la ejecución normativa, la introducción de un mecanismo de repercusión equilibrado puede ayudar a solucionar algunas de las patologías derivadas de la falta de participación de éstas en la elaboración y ejecución del Derecho de la Unión; sin embargo, a tal fin deberán tenerse en cuenta -en igualdad de condiciones- los elementos que determinan una implicación estatal y, en consecuencia, el Estado central habrá de asumir con naturalidad la parte de responsabilidad que pueda serle imputable.

II. InCUMPLIMIENTO DEL DERECHO de LA Unión EUROPEA, SANCIÓN Y REPERCUSIÓN

Los casos en los que el Estado puede enfrentarse a la necesidad de asumir consecuencias económicas por acciones $u$ omisiones de entes descentralizados constitutivas de incumplimiento son variados, si bien pueden ser clasificados, en esencia, en dos tipos: de un lado, los relativos a procedimientos por incumplimiento ante el Tribunal de Justicia; de otro, los procedentes del incumplimiento de obligaciones sectoriales que llevan consigo correcciones financieras o imposición de sanciones, tales como las existentes en relación con la gestión de fondos europeos o las derivadas de las condiciones de contención del déficit.

Este trabajo se centrará particularmente en el primero de los supuestos, si bien a lo largo del mismo se realizarán algunas consideraciones respecto del segundo. La razón de ello radica en la consideración de que 
los problemas más interesantes desde la perspectiva de la responsabilidad concurrente entre Estado central y comunidades autónomas se plantean en mayor medida en relación con aquél.

\section{Procedimiento por incumplimiento y procedimiento por inejecución}

EI art. 4.3 TUE, tras reconocer el deber de cooperación leal entre la Unión Europea y los Estados miembros, establece la obligación de éstos de adoptar «todas las medidas generales o particulares apropiadas para asegurar el cumplimiento de las obligaciones derivadas de los Tratados o resultantes de los actos de las instituciones de la Unión». Los Estados que así no lo hicieren podrán ser declarados responsables de incumplimiento por la vía del instrumento previsto en el art. 258 TFUE y, en caso de persistencia en el mismo, condenados al pago de una multa coercitiva o de una suma a tanto alzado, tal y como establece el art. 260 TFUE $^{1}$. Se trata del conocido doble procedimiento por incumplimiento y por inejecución que permite a la Comisión Europea ejercer su labor de vigilancia del cumplimiento de los Tratados y al Tribunal de Justicia de la Unión Europea su función jurisdiccional de declarar eventuales incumplimientos y, en su caso, de condenar al Estado que inejecuta una sentencia declarativa de incumplimiento al pago de una sanción económica.

Durante la tramitación de sendos procesos, el único interlocutor válido - con la Comisión primero y con el Tribunal de Justicia despuéses la Administración General del Estado, aunque el incumplimiento provenga de la acción u omisión de un ente territorial descentralizado². Es

\footnotetext{
1 Para un estudio en profundidad de esta cuestión, puede verse I. MARTín DelGado (2004), El procedimiento por inejecución en la justicia europea, Centro de Estudios Políticos y Constitucionales, Madrid, así como las consideraciones formuladas con posterioridad en «La eje cución de las sentencias declarativas del incumplimiento del Derecho Comunitario», Revista Española deDerecho Europeo, 16, 2005, págs. 595-626 y, más recientemente, «EI procedimiento por inejecución como garantía del sistema jurisdiccional europeo», Revista de Derecho Comunitario, Internacional y Derechos Humanos, 3, 2014, disponible en http://www.derechocomunitario.ucr.ac.cr/index.php?option $=$ com content $\&$ view $=$ article\&id $=830 \% 3 A 2014-11-30-22-36$ 24\& catid=31\%3A2014-11-30-20-28-05\& Itemid=4.

2 Con el intento de solucionar estos problemas, algunos autores han buscado fundamentar la imputación de la responsabilidad directamente a las regiones. GIL IBÁÑEZ denomina a esta idea «descentralización de responsabilidad» y consiste, en esencia, en que «los Estados miembros serían, en principio, los competentes para la resolución de todas las infracciones del Derecho Comunitario que hayan ocurrido en su territorio. Sin embargo, si la violación continúa después de un periodo de tiempo razonable, y la Comisión considera que la resolución del problema es importante para la aplicación uniforme del Derecho Comunitario, ésta podría actuar directamente contra la autoridad regional o local responsable de la violación, siempre que el Estado miembro en cuestión estuviera de acuerdo». Este sistema tendría dos ventajas, señaladas por el mismo autor: las relaciones serían más fáciles, pues se entablan directamente entre la Comisión y el ente materialmente responsable del incumplimiento y las posibles
} 
cierto que la práctica habitual de la Comisión E uropea es mantener contactos informales con los autores materiales del incumplimiento cuando éstos son entes descentralizados, como también lo es que, en el caso de España, algunos Estatutos de Autonomía han procedido a incorporar la dimensión europea en el ejercicio de las competencias autonómicas, regulando mecanismos de participación —orgánica y procedimentalen los procesos de toma de decisiones por parte de las instituciones de la Unión Europea, e incorporando deberes de consulta en la ejecución y desarrollo del Derecho de la Unión ${ }^{3}$. Además de ello, en lo que ahora interesa, junto con la facultad de acceder al Tribunal de J usticia cuando resulte posible en aplicación de la normativa europea, se prevé tanto la facultad de la comunidad autónoma de instar al Gobierno del Estado a iniciar acciones ante el mismo en defensa de los legítimos intereses y de las competencias autonómicas como la colaboración en la defensa jurídica en el marco de tales procedimientos. La petición de la comunidad autónoma no vincula al Estado, si bien algunos Estatutos prevén que el Gobierno deba motivar su negativa (así lo hace el Estatuto de Cataluña en su art. 191). De este modo, se está procediendo a elevar el rango normativo, a través del Estatuto de Autonomía, de parte del Acuerdo de la Conferencia para Asuntos Relacionados con la Unión Europea de 11 de diciembre de 1997, sobre la participación de las comunidades autónomas en los procedimientos ante el Tribunal de Justicia. Con carácter singular, el art. 233 del Estatuto de Autonomía de Andalucía contempla expresamente el deber del Estado de informar a la J unta de Andalucía, en lo que afecte al interés de la comunidad autónoma, sobre los procedimientos que se sigan ante los órganos judiciales europeos en los que España sea parte, pudiendo ésta presentar las observaciones que estime procedentes.

Sin embargo, como resulta evidente, en ningún caso se sitúa a la comunidad autónoma en una posición independiente, con capacidad plena de plantear la defensa de sus intereses en el marco del procedimiento ante el Tribunal de Justicia y de los contactos informales y formales de

sanciones se impondrían directamente al mismo, con lo que la efectividad del mecanismo del artículo 260.2 podría ser mayor. Ello, no obstante, exigiría una reforma de los artículos 258 y 260 TFUE. Véase. The Administrative Supervision and Enforcement of EC Law: Powers, Proce dures and Limits, Hart Publishing, Oregón, 1999, págs. 146 y 319.

3 En su Informe de 14 de febrero de 2008, sobre la integración del Derecho Europeo en el ordenamiento español, el Consejo de Estado señaló la necesidad de fomentar la participación de las comunidades autónomas en los asuntos europeos; en particular, en lo que ahora interesa, destacó la importancia de permitir la defensa de la actuación autonómica en el marco del procedimiento por incumplimiento como contrapartida al eventual ulterior traslado de la responsabilidad.

Lo que no han incorporado los nuevos Estatutos ha sido la regulación de la asunción de la responsabilidad por infracción del Derecho de la Unión. 
carácter previo con la Comisión que se dan en el recurso por incumplimiento. Prevalece, en última instancia, la posición de los servicios jurídicos del Estado.

Como ha sido anticipado, de conformidad con lo previsto en el art. 260 TFUE, el Reino de España puede ser condenado al pago de una suma a tanto alzado y/o de una multa coercitiva como consecuencia de la inejecución de una sentencia declarativa del incumplimiento de obligaciones derivadas del Derecho de la Unión y, además, también por falta de comunicación de las medidas de transposición de una Directiva. Efectivamente, la entrada en vigor del Tratado de Lisboa ha supuesto una importante novedad en cuanto a los mecanismos de garantía del cumplimiento del Derecho de la Unión Europea. J unto al procedimiento por incumplimiento - que permitea la Comisión solicitar al Tribunal de J usti cia que declare que un Estado miembro ha incumplido sus obligaciones derivadas del Derecho de la Unión Europea- y al procedimiento por inejecución -que puede suponer la imposición de una multa coercitiva o de una suma a tanto alzado al Estado miembro recalcitrante que no ha procedido a adoptar las medidas necesarias para ejecutar una sentencia declarativa del incumplimiento- se ha introducido la posibilidad desancionar a los Estados miembros por no comunicar en plazo las medidas de transposición de una Directiva. Así lo hace el tercer apartado del art. 260 del Tratado de Funcionamiento de la Unión Europea cuando dispone que la Comisión, en el momento de presentar un recurso ante el Tribunal de J usticia por considerar que un Estado miembro ha incumplido la obligación de informar sobre las medidas de transposición de una Directiva, podrá indicar el importe de la multa coercitiva o la suma a tanto alzado que deba ser pagada por el mismo, correspondiendo al Tribunal la imposición de su pago. Con este mecanismo sancionador se busca reaccionar frente a los retrasos de los Estados miembros en la transposición de Directivas.

Como pone de manifiesto una simple lectura del tenor literal del art. 260 TFUE, son escasas las pautas normativas para la determinación del régimen jurídico del procedimiento por inejecución; no se indican límites, ni criterios de imposición, ni, en general, los principios que ha de seguir su aplicación. Éste fue el motivo por el que la Comisión publicó, en 1996 y 1997, dos Comunicaciones en las que establecía los criterios que iba a seguir para la determinación y el cálculo de las medidas sancionadoras 4 . Posteriormente, tomando ya como referencia las primeras

4 Comunicación sobre la aplicación del artículo 171 del Tratado CE (DOCE C 242/96) y Comunicación sobre el método de cálculo de la multa coercitiva prevista en el art. 171 del Tratado CE (DOCE C 3/97). 
sentencias del Tribunal de Justicia en aplicación del mismo, refundió ambas comunicaciones en una sola, la Comunicación sobre la aplicación del art. 228.2 CE, de 13 de diciembre de 2005 (SEC (2005) 1658), que ha sido modificada en varias ocasiones con la finalidad de actualizar los datos que sirven de base para el cálculo de la multa coercitiva y la suma a tanto alzado ${ }^{5}$. Además, en el año 2010 emitió una Comunicación sobre la aplicación del art. 260.3 TFUE (SEC (2010) 923).

No resulta posible, por razones de espacio, analizar críticamente los contenidos de estos documentos. Baste decir que en ellos se identifican los criterios que la Comisión está aplicando a la hora de ejercer la labor a ella encomendada por el art. 260 TFUE. En particular, en la determinación del importe delas medidas sancionadoras, son tres los elementos que considera: la gravedad de la infracción (en un intervalo de 1 a 20), para lo que se tienen en cuenta, entre otros criterios, la importancia de las normas infringidas y las consecuencias que la infracción tiene para los intereses generales y particulares; la duración de la misma (en un intervalo de 1 a 3), que comienza a computarse desde la adopción de la sentencia del Tribunal de Justicia declarativa del incumplimiento hasta la presentación del recurso por inejecución; y la eficacia de las sanciones, de tal modo que el importe de las mismas deberá ser lo suficientemente elevado como para surtir un efecto de corrección del incumplimiento en los Estados miembros y para evitar que sea más beneficioso el incumplimiento que el cumplimiento, así como lo suficientemente respetuoso con el principio de proporcionalidad.

El método de cál culo de la multa coercitiva sigue una fórmula matemática, nada sencilla pero muy bien explicada por la Comisión, consistente en dos operaciones: multiplicación de un tanto alzado de base uniforme (cantidad fija y común para todos los Estados, actualmente fijada en 670 euros) por un coeficiente de gravedad y un coeficiente de duración (variables en función del caso concreto) y multiplicación de la cantidad obtenida como consecuencia de esa primera operación por un factor fijo por país, denominado «factor $n »$, que tiene en cuenta la capacidad de pago del Estado miembro afectado y el número de votos de que dispone en el Consejo.

Respecto de la suma a tanto alzado, la Comisión ha optado por una suma a tanto alzado mínima de carácter fijo para cada Estado miembro y por una suma variable que se concreta a través de un método de cálcu-

${ }^{5}$ La última actualización a fecha de cierre de este trabajo es la contenida en la Comunicación sobre actualización de los datos para calcular las sumas a tanto alzado y las multas coercitivas que propondrá la Comisión al Tribunal de Justicia en los procedimientos de infracción (COM (2015) 5511 final, de 5 de agosto). 
lo basado en un importe diario (calculado mediantela multiplicación de un tanto alzado de base uniforme por un coeficiente de gravedad, en un intervalo de 1 a 20, cuyo resultado se multiplica por un factor $n$ ), que se multiplica, a su vez, por el número de días de persistencia en la infracción. En el caso concreto, se propondrá la condena al pago de la suma a tanto alzado de cuantía más elevada, esto es, la fija o, de resultar mayor, la variable. EI tanto alzado de base uniforme está fijado actualmente en los 220 euros. Para España se ha establecido una suma a tanto alzado mínima de 6.949.000 euros.

La explicación del método de cálculo de la multa coercitiva y de la suma a tanto alzado se justifica por el hecho de que permite demostrar que en él se tienen en cuenta no sólo criterios relativos al concreto incumplimiento, sino también elementos adicionales tales como la reiteración o la actitud ante el mismo. De este modo, en el caso de incumplimientos autonómicos, si bien la cuantía final vendrá determinada principalmente por criterios de cálculo que toman en consideración circunstancias únicamente imputables al sujeto incumplidor, una parte puede responder a factores que no dependen del mismo - condenas previas al Reino de España en ámbitos materiales y supuestos similares, aunque no correspondan a la misma comunidad autónoma, o actitud de pasividad en la respuesta a las consideraciones de la Comisión Europea en sus cartas de emplazamiento o en su dictamen motivado, por señalar dos ejemplos-. Así, se estaría obligando a una comunidad autónoma a aceptar la repercusión de una sanción en una cuantía de la que no es totalmente responsable; por ello, tanto la declaración de responsabilidad que efectúa el Consejo de Ministros en el procedimiento de repercusión de sanciones impuestas al Reino de España por incumplimientos autonómicos como la determinación de la cantidad a repercutir deberían tomar en consideración esta realidad. Más adelante se profundizará en esta idea.

En su XXXI Informe anual sobre el control de la aplicación del Derecho de la Unión Europea correspondiente al año 2013 (COM (2014) 612 final), la Comisión Europea señala que los retrasos en la transposición y la notificación de Directivas constituyen un problema persistente. A fecha de 31 de diciembre de 2013, eran 390 los procedimientos por transposi ción tardía de Directivas abiertos por la Comisión, 13 de ellos frente a E spaña. En 14 casos la Comisión ha solicitado la imposición de una sanción económica al Estado incumplidor en aplicación de lo previsto en el art. 260.3 TFUE, ninguno de los cuales afecta, sin embargo, a nuestro país. En ese mismo año, 113 sentencias declarativas del incumplimiento estaban pendientes de ejecución; 14 de ellas frente a España, que encabeza el ranking. 
De conformidad con los datos publicados en el Informe de la Comisión sobre el Control de la aplicación del Derecho de la Unión (COM (2015) 329 final, de 9 de julio), a fecha de 31 de diciembre de 2014 son 1.347 los procedimientos por incumplimiento en tramitación, 86 de ellos frente a España (de los cuales, 19 tienen su origen en transposición tardía de Directivas). Se han iniciado 893 nuevos procedimientos, 42 de ellos contra España. De las 38 sentencias dictadas por el Tribunal de J usticia con arreglo al art. 258 TFUE, la mayor parte de ellas lo fueron contra España (18) y todas ellas a favor de la Comisión. Son 61 los procedimientos por inejecución abiertos, 8 de los cuales afectan a España - que nuevamente encabeza el listado de países inejecutores.

En 2014 se dictaron cinco nuevas sentencias por inejecución, una de ellas contra E spaña (en relación con el asunto de las vacaciones fiscales de las Diputaciones Forales vascas). Nuestro país no tiene pendiente ningún procedimiento por transposición tardía de Directivas en el que se haya solicitado la imposición de una sanción' ${ }^{6}$.

Aunque, como señala la Comisión, Ios Estados terminan transponiendo la Directiva antes de la sentencia condenatoria en el marco del art. 260.3 TFUE, lo hacen en fases muy tardías del procedimi ento ${ }^{7}$. Hasta el momento ha venido solicitando la imposición de multas coercitivas, pero ya ha dejado entrever su intención de solicitar sumas a tanto alzado para corregir esta situación.

No existen datos oficiales acerca de cuántos de estos incumplimientos corresponden a actuaciones u omisiones procedentes de órganos de las comunidades autónomas. Algunos estudios doctrinales ponen de manifiesto que se trata de una minoría, pues en la mayor parte de los casos el responsable es el Estado ${ }^{8}$. Con independencia de ello, resulta evidente que España suele encabezar los rankings anuales de incumpli-

6 De conformidad con los datos facilitados por la Secretaría de Estado para la Unión E uropea en respuesta a una solicitud de acceso a información pública planteada en aplicación de lo previsto en la Ley 19/2013, de 9 de diciembre, de Transparencia, Acceso a la Información Pública y Buen Gobierno, a fecha de 17 de septiembre de 2015 el Reino de España tiene 17 Directivas en proceso de incorporación al Derecho interno cuyo plazo de transposición ya ha vencido y se han iniciado procedimientos por incumplimiento en relación con 11 de ellas, si bien en ninguno de estos casos se ha planteado hasta el momento la imposición de una multa coercitiva o una suma a tanto alzado.

7 El plazo medio de duración de un procedimiento ordinario por incumplimiento es de 24 meses. Cuando el incumplimiento se refiere a la no comunicación de medidas de transposición de Directivas, la media está en los 15 meses.

8 Véase. M. Cienfuegos MATEO (2014), «La repercusión en España de las sanciones impuestas al Estado por infracciones del Derecho de la Unión Europea: desarrollos normativos y jurisprudenciales recientes», Revista Vasca deAdministración Pública, 98, pág. 56, quien afirma que de las 59 sentencias de incumplimiento dictadas contra España entre 2005 y 2009 sólo en 16 de los casos había implicación autonómica y en 7 de ellos la responsabilidad autonómica era consecuencia de aplicación de normativa estatal contraria al Derecho de la Unión. 
mientos e inejecuciones - 0 , en todo caso, estar situada en los primeros puestos- y, por tanto, el riesgo de sanción es relevante. Dicho sencillamente, aunque no pueda hablarse de un problema estructural en el cumplimiento del Derecho de la Unión ${ }^{9}$, sí existe una realidad merecedora de atención: las comunidades autónomas incumplen el Derecho de la Unión y de ese incumplimiento se derivan sanciones que ha de pagar el Estado central. No estamos ante una cuestión teórica, sino práctica. Aunque la situación fáctica que se está produciendo en los últimos años no sea lo suficientemente relevante como para justificar la incorporación en nuestro texto constitucional de mecanismos de sustitución de las comunidades autónomas por parte del Estado para prevenir incumplimientos o reaccionar frente a los mismos, no menos cierto es que resulta preciso normalizar la existencia de un mecanismo de repercusión de las sanciones impuestas que atienda al grado de responsabilidad de los actores intervinientes en el incumplimiento.

En este sentido, puede afirmarse que la repercusión de las responsabilidades económicas derivadas del incumplimiento del Derecho de la Unión Europea por las comunidades autónomas constituye, sobre el plano teórico, un instrumento de normalización del sistema. Cuestión muy diferente es si, dada la concreta forma en la que se ha regulado en nuestro ordenami ento jurídico, se ha logrado este objetivo normalizador o, más bien, se han introducido a través del mismo nuevos elementos perturbadores.

9 De esta opinión es M. AzPITARTE, quien sostiene la afirmación sobre la base de los datos derivados de las sentencias de incumplimiento frente a España entre 2005 y 2010, en relación con los cuales el principal incumplidor es el Estado central y no las comunidades autónomas, «La responsabilidad por incumplimiento y el orden constitucional de competencias: ¿una conexión necesaria?», en P. Biglino Campos y L. E. Delgado del Rincón (2011), El incumplimiento del Derecho Comunitario en el Estado Autonómico, Centro de Estudios Políticos y Constitucionales, Madrid, pág. 258. Este autor se muestra especialmente crítico con las conse cuencias que se derivan de los planteamientos del Consejo de Estado, tanto en su informe de 2008 como en el de 2010, por entender que las propuestas de reforzamiento de los poderes del Estado central en relación con la ejecución del Derecho de la Unión están construidas sobre la base de una realidad inexistente - el efecto perturbador de las comunidades autónomas en la incorporación del Derecho de la Unión y su influencia en la responsabilidad del Estado-. Véase. «EI Estado autonómico unitario y el Informe del Consejo de Estado sobre la inserción del Derecho Europeo en el ordenamiento español», Revista d'Estudis Autonòmics i Federals, 9, 2009, págs. 129-164. 
2. La repercusión de las consecuencias económicas derivadas del incumplimiento

A) La (deficiente) regulación del mecanismo de repercusión dela responsabilidad

Es jurisprudencia constitucional consolidada el reconocimiento de la facultad del Estado para establecer «los sistemas de compensación interadministrativa de la responsabilidad financiera que pudiera generarse para el propio Estado en el caso de que dichas irregularidades o carencias (las relativas al incumplimiento del Derecho de la Unión Europea) se produjeran efectivamente y así se constatara por las instituciones comunitarias» (por todas, la primera de las Sentencias con la que el Tribunal Constitucional inició esta línea jurisprudencial, la STC 79/1992, de 28 de mayo).

Hasta el año 2011, el legislador español había optado por ir integrando ad casum en la legislación sectorial -así lo hizo en materia de aguas, fondos europeos, subvenciones, comercio minorista o actividades de servicio, por señalar algunos ejemplos ${ }^{10}$, no pocos de ellos pensados para casos concretos en los que el Reino de España había si do sancionado o iba a serlo- una cláusula que preveía el deber de la Administración incumplidora de asumir la parte de responsabilidad que le fuere imputable y la posibilidad por parte del Estado de reclamar a la misma el pago de la cantidad a la cual había sido condenado en proporción al grado de responsabilidad.

Fue la Ley 2/2011, de 4 de marzo, de Economía Sostenible, la que incorporó a nuestro ordenamiento jurídico una cláusula general de repercusión de la responsabilidad, aplicable a todo tipo de incumplimientos de obligaciones derivadas de normas de Derecho de la Unión Europea.

La generalización de la cláusula de repercusión no sólo responde a razones de técnica legislativa - contar con cobertura para poder repercutir las sanciones impuestas ante cualquier tipo de incumplimiento, con independencia de su ámbito material, algo que había sido señalado como con-

10 Para un examen detallado de los mismos, puede verse P. A. SÁEnZ de SANTA María (2013) «Comunidades Autónomas y repercusión económica ad intra de las sanciones pecuniarias en el recurso por incumplimiento ante el Tribunal de J usticia de la Unión Europea», Revista Catalana de Dret Públic, 47, págs. 44 y ss.; M. Gómez PuENTE, «La repercusión interna de la responsabilidad por incumplimiento del Derecho Comunitario», texto provisional de la Conferencia impartida en el Foro de las Autonomías el 18 de febrero de 2015, págs. 13 y ss., disponible en http://idpbarcelona.net/docs/intranets/incumplimientoue 2014.pdf (última fecha de consulta: 12/8/2015); y M. Cienfuegos MATEO, «La repercusión en Ē spaña de las sanciones impuestas al Estado...», op. cit., págs. 66 y ss. 
veniente por el Consejo de Estado en su Informe de 2010—, sino, sobre todo, a dos novedades que se habían producido en los últimos años: de un lado, la incorporación del tercer apartado del art. 260 TFUE que, como ha sido expuesto, permite la imposición de una suma a tanto alzado o de una multa coercitiva en el contexto de un procedimiento por incumplimiento ante la falta de comunicación en plazo de medidas de transposición de Directivas europeas; de otro, la inminente condena al Reino de España al pago de 20 millones de euros en el asunto Magefesa, que finalmente se materializó, como se analizará más adelante.

Esta cláusula, con ligeras modificaciones, ha pasado a la Disposición Adicional Segunda de la Ley Orgánica 2/2012, de 27 de abril, de Estabilidad Presupuestaria y Sostenibilidad Financiera ${ }^{11}$ que, además, reconoce en su artículo 8 la responsabilidad de las Administraciones Públicas que provoquen o contribuyan a producir el incumplimiento de los compromisos adquiridos por España de acuerdo con la normativa europea y, en consecuencia, les impone el deber de asumir en la parte que les sea imputable las responsabilidades que se hubieran derivado de tal incumplimiento. En línea con este precepto, bajo el título «Responsabilidad por incumplimiento de normas de Derecho de la Unión Europea o de tratados o de convenios internacionales de los que España sea parte», la citada Disposición Adicional Segunda establece lo siguiente:

1. Las Administraciones Públicas y cualesquiera otras entidades mencionadas en el apartado 2 del artículo 2 de esta Ley que, en el ejercicio de sus competencias, incumplieran obligaciones derivadas de normas del derecho de la Unión Europea o de tratados o convenios internacionales en los que

11 La Disposición Adicional Primera de la LES ha sido finalmente derogada por el Real De creto-ley 7/2013, de 28 de junio, de medidas urgentes de naturaleza tributaria, presupuestaria y de fomento de la investigación, el desarrollo y la innovación, que además -con la excepción razonable de la incluida en la Ley de Subvenciones y la, más sorprendente, relativa a la Ley 7/1996, de 15 de enero, de Ordenación del Comercio Minorista - procedió asi mismo a la derogación de todas las normas que con carácter sectorial regulaban un procedimiento específico para la determinación y repercusión de las responsabilidades derivadas del incumplimiento de la normativa europea, todo ello con el fin de eliminar la dispersión normativa existente en la materia. Se pone fin de este modo a una situación denunciada por la doctrina (véase, SÁENZ DE SANTA MARíA, «Comunidades Autónomas y repercusión económica...», op. cit., págs. 50-52), si bien no de forma completa. Efectivamente, con la supresión de todas estas previsiones se ha llegado a una situación en la que la cláusula general de repercusión se encuentra ubicada en una Ley Orgánica dedicada a garantizar el cumplimiento del principio de estabilidad presupuestaria; junto con ello, no se ha corregido la carencia denunciada por el Consejo de Estado en su Informe de 2010: la falta de concreción de la cláusula en relación con las reglas de imputación y los aspectos formales de la misma.

La redacción actual de la Disposición Adicional Segunda LOEPSF procede de la Ley Orgánica 9/2013, de 20 de diciembre, de control de la deuda comercial en el sector público, que ha extendido la responsabilidad y la posibilidad de repercusión a los incumplimientos de obligaciones derivadas de cualquier tratado o convenio internacional y ha aclarado el ámbito subjetivo de aplicación para equipararlo al de la propia LOEPSF. 
España sea parte, dando lugar a que el Reino de España sea sancionado por las instituciones europeas, o condenado por tribunales internacionales o por órganos arbitrales, asumirán, en la parte que les sea imputable, las responsabilidades que se devenguen de tal incumplimiento, de conformidad con lo previsto en esta disposición y en las de carácter reglamentario que, en desarrollo y ejecución de la misma, se dicten.

2. El Consejo de Ministros, previa audiencia de las Administraciones o entidades afectadas, será el órgano competente para declarar las responsabilidades previstas en los apartados anteriores y acordar, en su caso, la compensación o retención de dichas deudas con las cantidades que deba transferir el Estado a la Administración o entidad responsable por cualquier concepto, presupuestario y no presupuestario. En dicha declaración se tendrán en cuenta los hechos y fundamentos contenidos en la resolución de las instituciones europeas, de los tribunales internacionales o de los órganos arbitrales y se recogerán los criterios de imputación tenidos en cuenta para declarar la responsabilidad. El acuerdo se publicará en el Boletín Oficial del Estado.

3. Se habilita al Gobierno para desarrollar reglamentariamente lo establecido en la presente disposición, regulando las especialidades que resulten aplicables a las diferentes Administraciones Públicas y entidades a que se refiere el apartado 1 de esta disposición.

En desarrollo de esta habilitación normativa se ha dictado el Real Decreto 515/2013, de 5 de julio, por el que se regulan los criterios y el procedimiento para determinar y repercutir las responsabilidades por incumplimiento del Derecho de la Unión Europea.

De este modo, existe en nuestro ordenamiento jurídico tanto el presupuesto legal habilitante como el cauce procedimental necesario para declarar la responsabilidad por el incumplimiento del Derecho de la Unión y repercutir las sanciones económicas derivadas del mismo en todos los sectores materiales de competencia de la Unión Europea.

Con esta regulación se ha pretendido dar respuesta a algunas de las dudas que planteaba el Consejo de Estado en su Informe de 15 de diciembre de 2010, en el que lleva a cabo un completo estudio del concepto de incumplimiento del Derecho de la Unión Europea por los Estados miembros y, en particular, de los mecanismos de prevención, de reacción y de repercusión de la responsabilidad por parte del Estado en los supuestos en los que el incumplimiento provenga de comunidades autónomas o entidades locales. Si bien la propuesta última del máximo órgano consultivo consistía en la elaboración de una Ley para la Garantía del Cumplimiento del Derecho de la Unión Europea, el legislador estatal ha optado finalmente por dejar de lado la regulación de even- 
tuales mecanismos de prevención y de reacción para evitar o poner fin a incumplimientos autonómicos o locales y ha tratado únicamente la cuestión de la repercusión de la responsabilidad.

Podría entenderse esta opción como una muestra del único interés del Estado central por la cuestión de la repercusión de las sanciones a las que previamente ha debido hacer frente en los casos en los que no es el autor del incumplimiento. En todo caso, ha de considerarse más bien como un paso más en la normalización de las relaciones entre Estado y comunidades autónomas en el contexto de la Unión Europea, a través del cual se hace posible que responda del incumplimiento el nivel territorial del que realmente procede.

Sin embargo, como ha sido anticipado, un análisis de la normativa pone de manifiesto que la normalización no es completa, en tanto que está excesivamente pensada para la protección de los intereses estatales y no para hacer posible una fluida relación de cooperación Estadocomunidades autónomas, como se verá a continuación.

Tal y como se deduce de su tenor literal, tanto el art. 8 como la Disposición Adicional Segunda LOEPSF reconocen la responsabilidad de cualquier Administración Pública territorial -incluida, al menos teóricamente, la estatal - , cuyas acciones u omisiones causen incumplimientos del Derecho de la Unión Europea que culminen en una sanción por las instituciones europeas, y les impone el deber de asumir la responsabilidad que de ello se derive.

Son varias las preguntas que se plantean a la hora de interpretar correctamente la citada disposición.

En primer lugar, qué ha de entenderse por incumplimiento. El concepto abarca tanto los incumplimientos normativos como los de carácter ejecutivo, es decir, cualquier contradicción entre una obligación de Derecho de la Unión Europea -esté contemplada en una norma jurídica o en una resolución judicial o administrativa- y una actuación nacional. En este sentido, la Comisión Europea suele destacar tres tipos de situaciones causantes de incumplimiento: falta de notificación en plazo de las medidas nacionales de transposición de Directivas; no conformidad o incumplimiento de los requisitos de la legislación de la UE por parte de la legislación nacional; y aplicación incorrecta, mala aplicación o nula aplicación del Derecho de la Unión ${ }^{12}$. En definitiva, como puede apreciarse, el incumplimiento de las obligaciones derivadas del Derecho de la Unión E uropea es una infracción objetiva, independiente del autor

12 Así lo hace en su Informe sobre el control de la aplicación del Derecho de la Unión correspondiente a 2014, disponible en http://ec.europa.eu/atwork/applying-eu-law/docs/annual report_32/com_2015_329_es.pdf (última fecha de consulta: 12/8/2015). 
(podrá provenir de cualquier autoridad del Estado miembro -Ejecutivo, Legislativo o J udicial-, de cualquier ámbito territorial), del contenido de la obligación, de su carácter normativo o ejecutivo y de la causa y los efectos que de ello se deriven ${ }^{13}$.

En segundo lugar, debe aclararse qué se entiende por sanción. EI concepto de sanción ha de ser interpretado en sentido amplio. De un lado, abarca tres mecanismos coercitivos: el previsto en el art. 260 TFUE, que incluye la posibilidad de doble condena al pago de una suma a tanto alzado - sanción en sentido estricto- y de una multa coercitiva -medio de ejecución forzosa-; el contemplado en el art. 108 TFUE en materia de ayudas de Estado; y, finalmente, el previsto en el art. 126 TFUE, que regula la posibilidad de imponer una multa al Estado que incumpla las recomendaciones dadas por el Consejo en el marco de un procedimiento por déficit excesivo. De otro lado, el mecanismo de repercusión de responsabilidad resultará asimismo de aplicación, en virtud de lo dispuesto en el art. 7 de la Ley 38/2003, de 17 de noviembre, General de Subvenciones, a las correcciones financieras practicadas como consecuencia de incumplimientos en materia de fondos europeos. En consecuencia, se entenderá que el Reino de España ha sido sancionado por las instituciones europeas siempre que una resolución de cualquiera de ellas (esencialmente, Consejo, Comisión y Tribunal de J usticia) tenga consecuencias económicas desfavorables - bien por imposición de multas, bien por pérdida de fondos.

Finalmente, surge la duda acerca de cómo se concreta el grado de responsabilidad de las Administraciones autoras del incumplimiento en el caso de que sean varias o, lo que es lo mismo, qué criterios de imputación han de ser tomados en consideración para determinar a quién corresponde la responsabilidad del incumplimiento que ha provocado la adopción de una decisión sancionadora. Resulta evidente que el principal criterio de imputación será el de la competencia, pero no puede ser el único. Otros elementos como el grado de intervención en las actuaciones, la duración del incumplimiento o la reincidencia, por señalar algunos de ellos, también resultarán relevantes.

EI Real Decreto 515/2013 ha venido a dar respuesta a algunas de estas dudas. A través de él se ha regulado un procedimiento de naturaleza no sancionadora que tiene por objeto trasladar la responsabilidad asumida por el Reino de España como consecuencia de la condena impuesta por una institución de la Unión E uropea al auténtico responsable del incumplimiento de la que ésta trae su causa.

13 De la misma opinión, M. Gómez PuENTE, «La repercusión interna de la responsabilidad por incumplimiento...», pág. 5. 
No es objeto de estas líneas analizar en profundidad el contenido de esta norma ${ }^{14}$, sino indicar las anomalías que presenta en cuanto a la distribución de responsabilidades entre Estado y comunidades autónomas por el incumplimiento del Derecho de la Unión Europea.

En este sentido, a pesar de que, de conformidad con lo dispuesto en el art. 1, resulta de aplicación a todos los sujetos previstos en la LOEPSF -es decir, las diferentes Administraciones territoriales y el resto de entidades públicas y privadas integrantes del Sector Público Estatal-y del hecho de que la regulación del procedimiento está redactada en términos generales con el fin de incluir a todos ellos, una lectura atenta de los casos de incumplimiento que se mencionan, de los trámites procedimentales y de la regulación de los mecanismos para hacer efectiva la repercusión pone de manifiesto que se está pensando únicamente en repercusión de cantidades satisfechas por el Estado en casos en los que la responsabilidad corresponde a comunidades autónomas, pero no a la inversa, es decir, en pérdidas patrimoniales de las comunidades autónomas por acciones u omisiones del Estado. Más adelante setendrá oportunidad de profundizar en esta cuestión.

Siguiendo lo previsto en el ya citado Informe del Consejo de Estado de 15 de diciembre de 2010 -tal y como reconoce el propio Real Decreto en su Exposición de Motivos-, el art. 3 concreta su ámbito objetivo de aplicación en los incumplimientos del Derecho de la Unión Europea, provocados por acción u omisión por cualquiera de las Administraciones anteriormente indicadas en el ejercicio de sus competencias o funciones, que culminen en sanciones al Reino de España impuestas por instituciones europeas con carácter ejecutivo.

Asimismo, contempla un concepto amplio de sanción, que incluye la imposición mediante sentencia, acto o decisión ejecutiva de las instituciones europeas de una suma a tanto alzado o una multa coercitiva, de correcciones financieras o de minoración de cuantías de fondos procedentes del presupuesto de la Unión «o cualquier otro acto adoptado por una institución, órgano u organismo de la Unión Europea que implique responsabilidades financieras para el Estado o la merma de cualquier

14 Un estudio completo de la misma puede verse en Sáenz de SANTA María, «Comunidades Autónomas y repercusión económica...», op. cit., págs. 52 y sS.; M. D. DE VICENTE RuIz (2014), «La hora de la responsabilidad interadministrativa ante incumplimientos de obligaciones europeas», Revista de Administración Pública, 193, págs. 407 a 422; J. D. J ANER TORRENS, «Infracción del Derecho de la Unión Europea y repercusión "ad intra" de sus consecuencias», Revista Española de Derecho Europeo, 50, págs. 15-40; M. Cienfuegos MATEO, «La repercusión en España de las sanciones impuestas al Estado...», op. cit., págs. 75 y ss.; y, recientemente, D. ORdóñez Solis (2015), «¿Cómo se derivan entre las Administraciones españolas las responsabilidades financieras por el incumplimiento del Derecho de la Unión Europea?», en Revista de Derecho Comunitario Europeo, 51, págs. 539 y ss. 
cantidad que le hubiera sido reconocida». Salvo que el concepto de Estado se entienda en sentido amplio, incorporando cualesquiera de sus niveles territoriales de gobierno y administración, nuevamente puede apreciarse en esta regulación una clara parcialidad en favor del Estado central y en detrimento de las comunidades autónomas. Efectivamente, de interpretar este precepto en sentido literal, no tendría cabida en el mismo el supuesto de responsabilidades financieras o merma de cantidades para las comunidades autónomas que sean consecuencia de una actuación u omisión de carácter estatal.

El concepto de incumplimiento es igualmente amplio, pues abarca toda actuación u omisión contraria al Derecho de la Unión Europea. El art. 3.3 enumera algunos supuestos, tales como la transposición, inejecución de sentencias o decisiones europeas, existencia de normas contrarias al Derecho de la Unión o «adecuación tardía o incorrecta de la normativa autonómica a la legislación básica estatal dictada en cumplimiento del Derecho de la Unión Europea». No menciona, sin embargo, otros posibles como pudieran ser la falta de ejercicio de la competencia estatal de coordinación en el marco de competencias autonómicas que exceden el territorio de una comunidad autónoma, los incumplimientos autonómicos que puedan derivarse del cumplimiento de la legislación básica estatal contraria al Derecho de la Unión o las indemnizaciones por daños a particulares causados por acciones autonómicas en aplicación de normativa estatal reclamadas por la vía de la responsabilidad por incumplimiento del Derecho de la Unión. Además, incluso la mención específica a la adecuación tardía o incorrecta de normativa básica estatal pone de manifiesto esa visión estatalista, dado que habrá responsabilidad en la medida en que exista incumplimiento del Derecho de la Unión, no por la simple falta de adecuación de la normativa autonómica a la básica estatal ${ }^{15}$.

A la hora de determinar la responsabilidad, el art. 4 señala que serán vinculantes para el Consejo de Ministros los contenidos de las sentencias, actos o decisiones ejecutivas de las instituciones europeas que contengan la sanción al Reino de España. Una correcta interpretación

15 Así lo pone de manifiesto SÁEnz de SANTA MARÍA, «Comunidades Autónomas y repercusión económica...», op. cit., pág. 54.

I gualmente indicativo de la excesiva protección de los intereses del Estado era parte del Preámbulo del Proyecto de Real Decreto (finalmente modificado y no incorporado a su versión definitiva) en el que se justificaba la facultad del Estado de repercutir la responsabilidades en el resto de Administraciones territoriales en «la participación de todas las Administraciones en la fase descendente de aplicación del Derecho de la Unión Europea», olvidando después que la propia Administración General del Estado es en nuestro país la principal aplicadora del Dere cho de la Unión y que, precisamente por ello, en los casos de competencias compartidas o de concurrencia de elementos de culpa de carácter estatal, también habrá de asumir su tanto de responsabilidad. 
de esta previsión permite afirmar el efecto vinculante de los contenidos de los documentos que anteceden a la sentencia del Tribunal de J usticia en el contexto del procedimiento por incumplimiento y del ulterior procedimiento por inejecución - las cartas de emplazamiento y el dictamen motivado- y de los informes de la Comisión Europea en el marco del procedimiento por déficit excesivo o de la gestión de fondos europeos, que sirven de base a la decisión del Consejo y que determinan las correcciones financieras, respectivamente.

En los casos de actuación u omisión conjunta de varias Administraciones que provoquen un mismo incumplimiento, la responsabilidad será mancomunada; con el fin de determinar el grado de responsabilidad que corresponde a cada una, se tendrán en cuenta los siguientes criterios -entre otros-: competencia, intensidad de la intervención, participación en la financiación asignada y reiteración. Sólo cuando no sea posible aplicar estos criterios, la distribución de la responsabilidad se realizará a partes iguales. Como puede observarse, con la excepción de la obligatoriedad de tener en cuenta los contenidos de la decisión europea de la que la sanción trae su causa, la aplicación del resto de criterios - Ios mencionados y los que no lo están ${ }^{16}$ _ quedan en el ámbito de la discrecionalidad del Consejo de Ministros ${ }^{17}$.

Entre los criterios recogidos no se mencionan otros que podrían ser útiles para determinar la posible responsabilidad estatal por culpa «in vigilando» o por una deficiente defensa de la posición nacional en el procedimiento que ha culminado con la resolución sancionadora para el Reino de España. En el análisis de los supuestos en los que se ha aplicado el mecanismo de repercusión se demostrará que estos criterios deberían haber sido tomados en consideración para responder a la responsabilidad concurrente que, de facto, se ha dado en ellos.

En cuanto al procedimiento de repercusión, regulado en los arts. 7 y ss. - que ha de entenderse como cauce formal para trasladar la responsabilidad, en la parte que le sea imputable, a la Administración o Administraciones autoras del incumplimiento que ha derivado en sanción y no como procedimiento sancionador ${ }^{18}$-, corresponderá con carácter

16 Gómez Puente señala algunos, tales como la población afectada, el impacto territorial, la diferente duración de la situación de contravención, la renuencia al cumplimiento, la intencionalidad o la diligencia puesta en el cumplimiento. «La repercusión interna de la responsabilidad por incumplimiento...», pág. 23.

17 SÁEnZ de SANTA MARíA, «Comunidades Autónomas y repercusión económica...», op. cit., pág. 55.

18 El propio Consejo de Estado, en su Informe 569/2013 sobre el proyecto de Real Decreto, consideró que se trata de un procedimiento de derivación de responsabilidades y no sancionador, avalando así lo que afirma el propio Real Decreto en su Exposición de Motivos. La importancia de determinar su naturaleza sancionadora o no radica en que, en el caso de poder 
general ${ }^{19}$ a la Secretaría General de Coordinación Autonómica Local del Ministerio de Hacienda y Administraciones Públicas la función de iniciarlo e instruirlo y al Consejo de Ministros la competencia para resolverlo. El procedimiento, que se inicia de oficio, no se tramitará en tanto que no se reciba por parte de la Secretaría de Estado para la Unión Europea (o el órgano competente a tal fin) la notificación de que la sentencia, acto o decisión de la institución europea por la que se impone la sanción al Reino de España es ejecutiva. Se renuncia con ello a intentar establecer contactos informales previos a la ejecutividad entre las Administraciones implicadas al efecto de avanzar un posible acuerdo que permita determinar los hechos, reconocer el grado de responsabilidad y concretar el importe de la deuda, tarea ésta que corresponderá en todo caso al órgano instructor a través del Acuerdo de iniciación de procedimiento de manera unilateral.

Uno de los puntos más débiles y discutibles del procedimiento que se está analizando es el relativo al trámite de audiencia en la fase de instrucción. Lejos de situar a las Administraciones territoriales implicadas en condiciones de igualdad y de permitir un adecuado diálogo a los efectos de garantizar el mejor cumplimiento del Derecho de la Unión Europea, el legislador y el Gobierno estatales han optado por introducir un simple trámite de alegaciones, con la mera posibilidad de aportar los documentos e informaciones que estimen convenientes y plantear la práctica de la prueba, atribuyéndoles la consideración de simples interesados en el procedimiento cuando, en realidad, en el mismo se está determinando no sólo el grado de participación que éstas han podido tener en el incumplimiento causante de la sanción, sino también la posible responsabilidad del propio Estado ${ }^{20}$. Nótese, además, que los informes que pueden ser solicitados por el órgano instructor a los efectos de concretar los hechos se refieren siempre a órganos estatales: Abogacía del Estado del Ministerio competente, Secretaría de Estado para la Unión

afirmarla, no resultaría de aplicación a la repercusión de sanciones impuestas con anterioridad a su entrada en vigor, en aplicación del principio de irretroactividad. Ello hubiera dejado sin cauce procedimental la repercusión de la sanción impuesta en el Asunto C-610/10.

Entre los autores que reconocen ciertos efectos sancionadores al procedimiento de repercusión se encuentra M. CiENFUEGOS MATEO, quien mantiene que, al menos indirectamente, el procedimiento es de naturaleza sancionadora en tanto que en el marco del mismo se determinan los responsables últimos de la infracción causante de la sanción y se repercute el montante a los autores materiales, «La repercusión en España de las sanciones impuestas al Estado....», op. cit., pág. 86.

19 Cuando el incumplimiento afecte a fondos procedentes de la Unión Europea la compe tencia para iniciar e instruir el procedimiento corresponderá a los órganos competentes para la coordinación de los mismos.

20 En sus observaciones al Proyecto de Real Decreto, las comunidades autónomas expresaron su crítica ante la falta de participación en el procedimiento. 
Europea y, precisamente en el caso en los que se considere que puede existir un incumplimiento atribuible en todo o partea la Administración General del Estado o a sus entidades instrumentales, al Departamento ministerial competente o la entidad presuntamente responsable. Ninguna mención se hace a los servicios jurídicos de las comunidades autónomas o a las Consejerías competentes.

La vía de la Conferencia para Asuntos Relacionados con la Unión Europea -órgano de cooperación que, de conformidad con la Ley 2/1997, de 13 de marzo, tiene como finalidad esencial garantizar la participación de las comunidades autónomas en la formación de la voluntad estatal ante las instituciones europeas y en la ejecución del Derecho

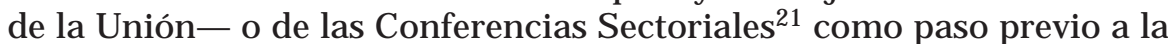
iniciación del procedimiento de repercusión de la responsabilidad para los casos de falta de acuerdo no deberían haberse descartado. El sistema actualmente vigente sitúa al Estado en una posición de superioridad que no se corresponde con la necesidad de normalizar las relaciones entre éste y las comunidades autónomas en lo relativo a la elaboración y aplicación del Derecho de la Unión Europea.

Tramitado el procedimiento, corresponde al Consejo de Ministros, en el plazo de seis meses desde el acuerdo de iniciación, resolver el mismo. La resolución es ejecutiva y abre la vía judicial.

EI Real Decreto contempla en su art. 15 la posibilidad de reconocer la responsabilidad y proceder al pago de la deuda en cualquier momento anterior a la resolución. Ello implica el hecho de que no se repercutirá el interés compensatorio de los costes financieros devengados. Aunque, en apariencia, el precepto busca facilitar el acuerdo entre las partes, en realidad simplemente está fomentando el reconocimiento previo de la autoría del incumplimiento por parte de las comunidades autónomas.

En todo caso, el pago debe efectuarse en los dos meses siguientes a la notificación del Acuerdo del Consejo de Ministros. J unto con el pago voluntario de la deuda, se regula la posibilidad de hacer uso de mecanismos de exacción, es decir, de proceder a la compensación, deducción o

${ }^{21}$ Es muy interesante, en este sentido, el Informe del Departamento de Administración Pública y J usticia del Gobierno Vasco relativo a la consulta sobre la aplicación de la Disposición Adicional Segunda LOEPSF y la aplicabilidad del Real Decreto 515/2013 que, sin cuestionar la competencia del Estado para establecer el principio de responsabilidad por incumplimiento del Derecho de la Unión, señala que la decisión sobre cualquier extremo relacionado tanto con los criterios de imputación, la distribución de la responsabilidad o el importe de la deuda, como las fórmulas para hacerla efectiva, deben pasar por el acuerdo de la Comisión Mixta del Concierto Económico. Dicho de otra manera, en opinión del Gobierno vasco, el procedimiento de repercusión de la responsabilidad previsto en la LOEPSF y desarrollado en el citado Real Decreto no sería de aplicación en relación con esta comunidad autónoma. 
retención de la deuda con cantidades que el Estado deba satisfacer a la Administración o entidad responsable.

Se ha evitado explorar una doble vía que se deriva de la práctica habitual de cobro de las sumas a tanto alzado y de las multas coercitivas por parte de la Comisión Europea en el marco de los recursos por inejecución ${ }^{22}$. En primer lugar, la relativa a la posibilidad de que el pago, previo acuerdo con la Administración autonómica responsable, sea realizado por ésta antes de que el Estado central satisfaga la deuda. Efectivamente, no debería haberse descartado la posibilidad de que la resolución del Consejo de Ministros hubiera previsto un plazo dentro del cual la Administración causante del incumplimiento proceda a efectuar el pago de la cantidad a la que ha sido condenado el Reino de España, con anterioridad al momento en el que la Administración General del Estado sea requerida para abonar la sanción en la cuenta correspondiente de la Unión Europea. De este modo se evitaría que la Administración General del Estado se viera obligada a responder con fondos propios de un incumplimiento del que no es responsable material (o no lo es totalmente, en los casos de concurrencia de responsabilidades) y no se incurriría en la obligación de pagar intereses. Para facilitar esta opción sería conveniente introducir en el procedimiento administrativo, como trámite obligatorio durante la instrucción del mismo sometido a un plazo necesariamente breve, la posibilidad de alcanzar un acuerdo sobre las formas y los plazos en que la Administración responsable ha de efectuar el pago.

De otro lado, tampoco se ha planteado la posibilidad de compensación, por parte de la Comisión Europea, con cantidades que tengan por destinataria a la Administración interna responsable del incumplimiento. Previo acuerdo entre la Administración General del Estado y la Administración causante del incumplimiento, podría negociarse con la Comisión Europea que ésta proceda a deducir al Reino de España las cantidades que vayan destinadas a la Administración responsable, de tal modo que no se ingresarían en la cuenta del Estado español y éste no

22 La Decisión de la Comisión de 17 de junio de 2011 (C (2001) 4112 final), por la que se aprueban las normas internas de procedimiento para el cobro de créditos derivados de la gestión directa y el cobro de sanciones, multas coercitivas y sumas a tanto alzado en aplicación de los Tratados, regula en su capítulo segundo el procedimiento de cobro de las sumas a tanto alzado y las multas coercitivas impuestas a los Estados miembros en aplicación de lo previsto en el art. 260 TFUE. De conformidad con lo previsto en ella, el oficial responsable en cada caso emitirá una carta de requerimiento del pago al mes siguiente de la notificación de la sentencia que impone una u otra medida, pago que deberá efectuarse en los 45 días siguientes a la recepción de la misma. En caso de incumplimiento del plazo, se requerirá nuevamente al Estado, esta vez a través de un apercibimiento formal, para que proceda al pago en 15 días. Si la respuesta es nuevamente negativa, se prevé la posibilidad de pago por deducción de cantidades adeudadas a aquél (incluyendo los intereses de demora). 
las transferiría a la misma. Al igual que en el caso anterior, una solución de este tipo debería incorporarse a la regulación del procedimiento de repercusión.

Para finalizar, debe tenerse en cuenta que la Disposición Derogatoria del Real Decreto deja sin efecto algunos preceptos de dos de los Reales Decretos que venían regulando hasta el momento la derivación de la responsabilidad en el ámbito de los fondos europeos (el Real Decreto $327 / 2003$, de 14 de marzo, por el que se regula el régimen de los organismos pagadores y de coordinación con el FEOGA-Garantía y el Real Decreto 1542/2011, de 31 de octubre, por el que se aprueba la Estrategia Española de E mpleo 2012-2014). Con ello se pone de manifiesto su vocación de aplicación general en relación con la repercusión de las responsabilidades económicas derivadas de los incumplimientos del Derecho de la Unión.

Puede concluirse este somero análisis del Real Decreto 515/2013 afirmando que su principal virtud consiste en haber incorporado a nuestro ordenamiento jurídico un cauce procedimental para repercutir la responsabilidad económica derivada del incumplimiento del Derecho de la Unión en los casos de actuaciones u omisiones imputables a las comunidades autónomas, mientras que su principal carencia consiste en haber omitido la mención expresa al caso para el cual precisamente resulta imprescindible: el de la corresponsabilidad del Estado central en el incumplimiento. Efectivamente, para determinar la responsabilidad y repercutir el montante de la sanción satisfecha por el Estado cuando aquélla corresponde en exclusiva eíntegramente a una comunidad autónoma, en puridad, no es necesario procedimiento alguno de declaración de responsabilidad, pues resulta evidente quién ha de pagar y existe título jurídico suficiente para exigir el pago. Su utilidad se encuentra en los supuestos en los que son varias las comunidades autónomas implicadas, así como en el caso (para nada descartable, como se verá más adelante) de participación directa o indirecta del Estado central en el incumplimiento o de toma en consideración en la sanción de elementos ajenos a la comunidad autónoma responsable. Si ello es así, resulta criticable que el papel de las comunidades autónomas afectadas quede reducido a un simple trámite de audiencia. Desde esta perspectiva se entienden mejor las críticas formuladas por parte de la doctrina en el sentido de que quien determina la responsabilidad y resuelve repercutirla es precisamente quien debe reconocer también su tanto de culpa. 


\section{B) La conflictividad provocada por la regulación}

La regulación de la responsabilidad derivada de incumplimientos autonómicos del Derecho de la Unión Europea llevada a cabo por el legislador y por el Real Decreto 515/2013 ha sido contestada por algunas comunidades autónomas, que han fundado sus recursos en parte de los argumentos expuestos en las páginas precedentes.

En particular, el Gobierno de Canarias promovió recurso de inconstitucionalidad contra la Disposición Adicional Segunda de la LOEPSF (entre otros preceptos), por entenderla afectada de cuatro vicios: riesgo de violación del derecho a la tutela judicial efectiva de la Administración a la que se imputa la responsabilidad por la falta de participación de ésta en el procedimiento sancionador ante las instituciones europeas; desconocimiento de la jurisprudencia del Tribunal Constitucional sobre las consecuencias del incumplimiento del Derecho de la Unión Europea, al encomendar al Consejo de Ministros la declaración de la responsabilidad por incumplimiento cuando ésta se deriva del ejercicio de competencias propias de la comunidad autónoma; exceso regulatorio en cuanto que el contenido de la Disposición no queda amparado por el art. 135 CE y no puede formar parte de una Ley Orgánica cuyo objeto es desarrollar los principios de estabilidad presupuestaria; e insuficiencia del acuerdo del Consejo de Ministros en los casos de compensación de créditos para cumplir con el requisito de que éstos sean líquidos, vencidos y exigibles.

El Tribunal ha resuelto el recurso en su Sentencia 215/2014, de 18 de diciembre. En relación con esta cuestión, rechaza la concurrencia de los vicios expuestos. En primer lugar, entiende que el derecho a la tutela judicial efectiva tiene su origen en la Constitución Española, que no rige en el ámbito del Derecho de la Unión Europea, donde la normativa aplicable prevé un procedimiento en el que el único interlocutor es el Gobierno estatal. J unto con ello, considera que el trámite de audiencia exigido en la Disposición Adicional Segunda LOE PSF y desarrollado en el Real Decreto 515/2013 y la ulterior posibilidad de control jurisdiccional del Acuerdo del Consejo de Ministros es suficiente para entender satisfecho el derecho a la tutela judicial efectiva en el contexto del procedimiento de repercusión. En segundo lugar, reitera su jurisprudencia sobre la facultad de repercusión al afirmar que, aun cuando, de conformidad con la doctrina constitucional, el incumplimiento del Derecho de la Unión Europea no justifica la asunción por el Estado de competencias que no le corresponden, tampoco le impide «repercutir ad intra, sobre 
las Administraciones públicas autonómicas competentes, la responsabilidad que en cada caso proceda» $y$, en consecuencia, corresponde al Estado establecer «los sistemas de compensación interadministrativa de la responsabilidad financiera que pudiera generarse para el propio Estado en el caso de que dichas irregularidades o carencias se produjeran efectivamente y así se constatara por las instituciones comunitarias». Es por ello que entiende el Tribunal Constitucional que la atribución al Consejo de Ministros de la competencia para declarar la responsabilidad no lesiona la autonomía financiera de las comunidades autónomas. En tercer lugar, considera que una previsión como la contenida en la citada Disposición Adicional está amparada no sólo por el art. 135.5 CE, que reserva a ley orgánica la regulación de la responsabilidad de cada Administración Pública en el caso de incumplimientos de los objetivos de responsabilidad presupuestaria, sino también por la competencia del Estado para regular la materia relativa a la estabilidad presupuestaria que se deriva del art. 148.1 11ㅇ, 13으, 14ㅇ y 18ㅇ CE y para adoptar las medidas necesarias para logar el equilibrio presupuestario y la estabilidad económica. Por último, considera el Tribunal que el hecho de que la repercusión de responsabilidad se limite a deudas contraídas como consecuencia de decisiones ejecutivas adoptadas por las instituciones europeas permite cumplir con el requisito de que la cantidad repercutida esté vencida y sea líquida y exigible.

Olvida el Tribunal Constitucional23, sin embargo, que la aplicación de la Disposición Adicional Segunda LOEPSF, si bien está incluida en una norma cuyo objeto es «el establecimiento de los principios rectores, que vinculan a todos los poderes públicos, a los que deberá adecuarse

23 Un olvido en el que también ha incurrido el propio Gobierno al elaborar el Real Decreto. Llama la atención, como destaca J ANER TORRENS, que en la Exposición de Motivos del mismo no se haga mención alguna al art. 260 TFUE, sino únicamente al art. 135 CE y a la LOEPSF. «Infracción del Derecho de la Unión Europea y repercusión...», op. cit., pág. 33. Resulta evidente que la posición del Estado es más fuerte en el marco del control del déficit que en relación con los incumplimientos genéricos del Derecho de la Unión Europea declarados y sancionados posteriormente por la vía del procedimiento por inejecución o en la coordinación de fondos europeos. Basta una lectura general de la LOE PSF para comprobar la amplitud de los poderes de intervención que se atribuyen al mismo y compararlo con el papel de mera defensa procesal en el contexto del recurso de la Comisión Europea ante el Tribunal de Justicia o de mera gestión en el relativo a los fondos. Sin embargo, no ha de desconocerse una doble realidad: de un lado, la única cláusula genérica de repercusión de responsabilidad que pervive en nuestro ordenamiento jurídico es la contenida en la Disposición Adicional Segunda LOEPSF; de otro, la mayor parte de los supuestos de hecho que están dando y darán lugar a su aplicación guardan relación con este tipo de casos, y no con las sanciones por incumplimiento de las recomendaciones del Consejo en el procedimiento por déficit excesivo. Resulta, por ello, evidente, que la ubicación actual de la cláusula de repercusión no es la más adecuada. Paradójicamente el Consejo de Estado había recomendado en su Informe de 2010 la conveniencia de mantener una normativa específica para la repercusión de las responsabilidades financieras por déficit excesivo, por la singularidad del supuesto de hecho del que trae causa. 
la política presupuestaria del sector público orientada a la estabilidad presupuestaria y la sostenibilidad financiera, como garantía del crecimiento económico sostenido y la creación de empleo, en desarrollo del art. 135 CE», no se limita únicamente a los supuestos de imposición de multas por incumplimiento de las recomendaciones del Consejo en el contexto del procedimiento por déficit excesivo del art. 126 TFUE, sino que abarca igualmente las correcciones financieras en el marco de los fondos europeos y las sanciones económicas que el Tribunal de J usticia pueda imponer a un Estado miembro en cumplimiento de lo previsto en el art. 260 TFUE. Éste es precisamente el sentido de lo afirmado en el voto particular que contiene la citada Sentencia, firmado por los magistrados Adela Asúa Batarrita, Luis I gnacio Ortega Álvarez, Encarnación Roca Trías, Fernando Valdés Dal-Ré y Juan Antonio Xiol Ríos, al mantener en relación con esta cuestión que la LOEPSF vulnera la reserva de Ley Orgánica establecida en el art. 135.5 CE. Efectivamente, estos magistrados señalan que «la reserva de ley orgánica contenida en el art. 135.5 c) CE para regular la responsabilidad de cada Administración pública en caso de incumplimiento de los objetivos de estabilidad presupuestaria se extiende indebidamente en la disposición adicional segunda de la Ley Orgánica 2/2012 al genérico incumplimiento de las obligaciones derivadas de normas del derecho de la Unión Europea». Se produce con ello una vulneración por exceso, de tal modo que, en su opinión, debió entenderse infringida la reserva de Ley Orgánica del art. 135.5 c) CE, atribuyendo a la disposición adicional segunda de la Ley Orgánica 2/2012 el valor de ley ordinaria.

Por su parte, el Real Decreto 515/2013 ha sido impugnado en vía contencioso-administrativa ante el Tribunal Supremo por la Diputación de Bizkaia, al entender que la no inclusión en el mismo de una cláusula de salvaguarda del régimen foral es contraria a la Ley reguladora del Concierto Económico. El recurso aún no ha sido resuelto.

Finalmente, debe destacarse que el propio Gobierno de Canarias ha promovido un conflicto positivo de competencia ${ }^{24}$ en relación con el

24 Conflicto positivo de competencia n. 9 6893-2013, admitido por Providencia de 17 de diciembre de 2013. El conflicto fue presentado con Dictamen en contra del Consejo Consultivo de Canarias. Efectivamente, el Gobierno canario, en su Acuerdo de requerimiento al Gobierno del Estado, manifestaba que «si es la Administración competente por razón de la materia la que tiene que depurar en el orden interno su propia responsabilidad en el ejercicio de sus competencias, la concurrencia del interés de la Administración del Estado no puede llegar al nivel de una absoluta sustitución de la competencia autonómica (...), tanto más cuando el que decide de forma unilateral y ejecutiva es una de las partes implicadas, que se ve absolutamente interesada en la decisión porque tendría que asumir la responsabilidad en el caso de que no la pudiera derivar a otro». Ante tal afirmación, en su Dictamen 349/2013, de 17 de octubre, el órgano consultivo -en línea con lo ya afirmado en un Dictamen anterior a propósito de la impugnación de la Disposición Adicional Segunda de la LOEPSF - considera que el Real Decreto 
Real Decreto, que ha sido admitido a trámite por el Tribunal Constitucional y se encuentra pendiente de resolución.

Por otro lado, en el ámbito de los fondos europeos, el Gobierno de Aragón interpuso recurso de inconstitucionalidad en relación con el art. 7 de la Ley 38/2003, de 17 de noviembre, General de Subvenciones, en virtud del cual «2. Los órganos competentes de la Administración General del Estado para proponer o coordinar los pagos de las ayudas de cada fondo o instrumento, previa audiencia de las entidades afectadas mencionadas en el apartado anterior, resolverán acerca de la determinación de las referidas responsabilidades financieras. De dichas resoluciones se dará traslado al Ministerio de Hacienda para que se efectúen las liquidaciones, deducciones o compensaciones financieras pertinentes a aplicar a las entidades afectadas», de modo tal que «3. Las compensaciones financieras que deban realizarse como consecuencia de las actuaciones señaladas en el apartado anterior se llevarán a cabo por la Dirección General del Tesoro y Política Financiera, mediante la deducción de sus importes en los futuros libramientos que se realicen por cuenta de los citados fondos e instrumentos financieros de la Unión Europea, de acuerdo con la respectiva naturaleza de cada uno de ellos y con los procedimientos que se establezcan mediante orden conjunta de los $\mathrm{M} \mathrm{i-}$ nisterios de Economía y Hacienda, previo informe de los departamentos competentes».

Entiende el Gobierno autonómico que el sometimiento de la actuación administrativa autonómica a un poder estatal de supervisión y la consiguiente decisión ejecutiva vulnera el reparto competencial y afecta a la autonomía financiera de las comunidades autónomas, si se tiene en cuenta, además, que difícilmente puede considerarse que ese control estatal responda a la competencia de coordinación.

EI recurso fue resuelto por la Sentencia 130/2013, de 4 de junio. En su Fundamento Jurídico 9 D), tras afirmar el Tribunal Constitucional que la responsabilidad financiera de las comunidades autónomas, como consecuencia de su gestión de subvenciones financiadas por la Unión

no está regulando aspectos relativos a la ejecución del Derecho de la Unión, sino «un mecanismo de asignación de responsabilidades previsto para los de incumplimientos del Derecho de la Unión Europea que tiene por finalidad hacer efectiva en el presupuesto de la Administración incumplidora la sanción impuesta por las instancias europeas y de la que, en el plano exterior, responde únicamente el Estado». Es por ello que entiende que «el cumplimiento de la sanción y su repercusión a la Administración o Administraciones incumplidoras ha de quedar residenciado en la competencia estatal, sin que por ello puedan entenderse afectadas las competencias estatutariamente asumidas por las comunidades autónomas, pues no se trata del ejercicio por parte del Estado de competencias autonómicas, sino de hacer frente a las responsabilidades contraídas como Estado miembro de la Unión Europea, entre las que se encuentra el cumplimiento de las sanciones impuestas». En consecuencia, entiende que es conforme a Derecho. 
Europea, no puede ser determinada por la Administración del Estado de modo unilateral o previo, sino que resulta exigible que las irregularidades sean determinadas y constatadas por las propias instituciones europeas y ello genere, efectivamente, la responsabilidad financiera del Estado, entiende que la norma impugnada - muy imprecisa en relación con la posibilidad de que la propia Administración del Estado pueda determinar unilateralmente la responsabilidad, lo cual sería contrario al art. $153 \mathrm{CE}-$, es constitucional únicamentesi se interpreta entendiendo su conexión con el apartado 1 del precepto en el sentido de que «las responsabilidades que se deriven de dichas actuaciones» ha de sustentarse necesariamente en las correspondientes «decisiones de la Unión Europea» que generen la responsabilidad financiera del Estado. De acuerdo con ello, la resolución que adopten «los órganos competentes de la Administración General del Estado», dando traslado de las mismas al Ministerio de Hacienda, es una mera concreción técnica que permite trasladar en nuestro orden interno desde el Estado a la correspondiente comunidad autónoma la responsabilidad imputada a aquél por las instituciones europeas. J unto con ello, afirma que las decisiones que adopte el Ministerio de Hacienda «para que se efectúen las liquidaciones, deducciones o compensaciones financieras pertinentes» deberán estar siempre sometidas al control jurisdiccional, y, en su caso, al del propio Tribunal.

En definitiva, resulta evidente quela forma en que el Estado ha regulado la repercusión de la responsabilidad derivada del incumplimiento del Derecho de la Unión Europea ha suscitado conflicto, lo que pone de manifiesto que, lejos de estar ante una cuestión normalizada en nuestro ordenamiento jurídico, aún deben darse pasos para depurar su regulación y puesta en práctica. Aunque el Tribunal Constitucional haya avalado las líneas generales de la regulación contempladas a nivel legislativo, está por ver cómo se resuelven las impugnaciones, vía conflicto positivo de competencias y recurso contencioso-administrativo, del Real Decreto de desarrollo de las mismas.

3. La aplicación del mecanismo de repercusión por el Consejo de Ministros: solución a una cuestión controvertida

Una de las críticas que se han realizado a la regulación de la repercusión de la responsabilidad es la relativa a la falta de virtualidad práctica de la misma, debido principalmente al hecho de que la mayor parte de los incumplimientos proceden de actuaciones $u$ omisiones imputables 
al Estado y no a las comunidades autónomas y que muy rara vez los incumplimientos declarados terminan con la imposición de una sanción ${ }^{25}$. Aun pudiendo aceptarse que, desde el punto de vista cuantitativo, la aplicación del mecanismo de repercusión no será excesivamente relevante, no menos cierto es que cualitativamente los asuntos en los que, hasta el momento, se ha puesto en práctica sí lo son.

Los Acuerdos del Consejo de Ministros aprobados en aplicación del Real Decreto 515/2013 son publicados en el BOE como Anexo a Resoluciones de la Secretaría General de Coordinación Autonómica y Local (o del Fondo Español de Garantía Agraria y de la Secretaría de Estado de Empleo, en el caso de los fondos europeos), que tienen por objeto precisamente dar publicidad a los mismos. J unto con ello, la Disposición Adicional Tercera del Real Decreto establece la obligatoriedad del Ministerio de Hacienda y Administraciones Públicas de elevar al Consejo de Ministros un Informe - que será público- sobre las comunicaciones recibidas de actos, sentencias o decisiones de instituciones europeas por las que se sancione al Reino de España por incumplimiento, sobre los procedimientos tramitados en aplicación del Real Decreto y sobre el estado de ejecución de las resoluciones de los ya finalizados.

En este sentido, el pasado 17 de julio se ha presentado al Consejo de Ministros el primer informe, firmado por la Dirección General de Coordinación de Competencias con las comunidades autónomas y los entes locales ${ }^{26}$; de manera resumida, pone de manifiesto que hasta el momento se han tramitado 26 procedimientos de repercusión y se han repercutido un total de 77.634.759,98 euros a los responsables del incumplimiento, en todos los casos comunidades autónomas. La inmensa mayoría de los procedimientos - dos de ellos derivados de la imposición de una suma a tanto alzado y de una multa coercitiva con suma a tanto alzado en aplicación del art. 260 TFUE y el resto en materia de fondos europeos (Fondo de Garantía Agraria y Programa Operativo de Fomento del Empleo) - han sido resueltos sin ningún tipo de conflicto ni de debate, pues han finalizado por Acuerdo del Consejo de Ministros que recoge el acuerdo alcanzado entre el Estado y la comunidad autónoma correspondiente sin que éste haya tenido que proceder a declarar la responsabilidad o al cobro por vía ejecutiva, y se encuentran cerrados por

\footnotetext{
${ }^{25}$ En este sentido, J ANER TORRENS, «l nfracción del Derecho de la Unión Europea y repercusión...», op. cit., pág. 40.

${ }^{26} \mathrm{El}$ texto completo del informe está disponible en http://www.seap.minhap.gob.es/dms/ es/web/areas/politica_autonomica/participacion-ccaa-eu/ccaa_y_ue/Respons_incumpl_derecho UE/INFORME-ANNUAL-RD515-2013.def.02.06.15/I nforme\%202014.pdf (ūltima fecha de consulta: 11 de agosto de 2015).
} 
haber procedido esta última al abono de la deuda o aquél a la deducción de cantidades ${ }^{27}$.

Sin embargo, como se demostrará inmediatamente, la aquiescencia de las comunidades autónomas implicadas no es consecuencia de la inexistencia de aspectos controvertidos, sino más bien de una anomalía instaurada en nuestro ordenamiento jurídico. J unto con ello, nada impide que en el futuro se rompa esta aparente calma.

III. Algunas dudAs Sin Resolver: Responsabilidad CONCURRENTE Y REPERCUSIÓN A LA INVERSA

1. La corresponsabilidad de Estado en el contexto de incumplimientos autonómicos

Como ha tenido ocasión de comprobarse, la regulación de la repercusión de las responsabilidades derivadas del incumplimiento del Derecho de la Unión E uropea - tanto a nivel legislativo como en cuanto a su desarrollo reglamentario- está planteada desde una óptica eminentemente estatal: tras la tramitación del correspondiente procedimiento, que instruye un órgano integrado en la Administración General del Estado, corresponde al Consejo de Ministros determinar la responsabilidad y establecer la deuda, así como proceder al cobro por vía ejecutiva en caso de impago. La única participación de la comunidad o comunidades autónomas afectadas se restringe al trámite de audiencia, en el que interviene desde la condición de interesada en el procedimiento. Además, los criterios que se establecen para concretar la existencia de responsabilidad también ponen de manifiesto esa visión estatalista del asunto. Incluso el mecanismo de pago está claramente pensado sólo

27 Tal y como se expone en el citado Informe, sólo un caso (incumplimiento por parte de la comunidad autónoma de Extremadura de las Decisiones de Ejecución 2014/260/UE y 2014/251/UE, de 29 de abril, en materia de fondo de garantía agraria) se encuentra pendiente de ejecución en tanto que, a fecha de cierre del mismo, la comunidad autónoma implicada no había procedido a abonar el importe completo de la deuda, si bien el procedimiento de repercusión sí ha terminado con acuerdo entre las partes, y ha sido resuelto por Acuerdo del Consejo de Ministros de 19 de diciembre de 2014. Además, está en fase de tramitación el procedimiento iniciado en 2014 como consecuencia de correcciones financieras sufridas por el Reino de España por el incumplimiento de obligaciones en materia del programa operativo de fomento del empleo. En el Boletín Oficial del Estado se han publicado con posterioridad más acuerdos, todos ellos en materia de fondos europeos.

Para un examen en profundidad de la cuestión relativa a las correcciones financieras en materia de fondos europeos y la derivación de responsabilidades puede verse $D$. OrdóñEz SoLis, «¿Cómo se derivan entre las Administraciones españolas las responsabilidades financieras...», op. cit., págs. 552 y ss. 
para el supuesto en el que el Estado sea el beneficiario de las cantidades a repercutir ${ }^{28}$.

Se desprecia, en definitiva, la mención expresa a la posibilidad de que el Estado pueda ser responsable parcial de un incumplimiento y, en consecuencia, se vea obligado a asumir la parte de la responsabilidad que le sea imputable.

Sin embargo, una correcta interpretación del contenido del art. 5 del Real Decreto 515/2013 —redactado en términos lo suficientemente genéricos para permitirlo- hace posible entender que el Consejo de Ministros podrá, en su resolución al procedimiento de repercusión, determinar la parte de responsabilidad del Estado en el incumplimiento ${ }^{29}$. Efectivamente, no debe perderse de vista que el art. 8 LOEPSF habla de Administraciones Públicas «que provoquen o contribuyan a producir el incumplimiento de los compromisos asumidos por España» como las obligadas a asumir «en la parte que les sea imputable» las responsabilidades que de tal incumplimiento se deriven. No debe recibir las consecuencias sancionadoras únicamente la Administración autora directa del incumplimiento, sino también aquella que, sin serlo, ha influido en el mismo. De este modo, cuando concurren en el caso concreto elementos que remiten a actuaciones $u$ omisiones del Estado central ello ha de tener manifestación en la repercusión de la sanción, permitiendo la aplicación de la solución de la responsabilidad concurrente y, por tanto, que las Administraciones implicadas asuman la misma de manera mancomunada. Los criterios que se mencionan en orden a determinar el tanto de responsabilidad que corresponde a cada una de las Administraciones implicadas _-incluida la estatal — son sólo algunos de los que pueden resultar de aplicación en el caso concreto.

Un análisis de los dos asuntos tramitados hasta el momento en los que el Reino de España ha sido condenado al pago de una suma a tanto alzado y de una multa coercitiva por el Tribunal de J usticia de la Unión Europea pone de manifiesto que, en ambos casos, existían elementos suficientes para reconocer que el Estado era parcialmente responsable del incumplimiento o, lo que es lo mismo, en terminología de la LOEPSF,

28 En este mismo sentido, M. Cienfuegos M ATEo, para quien la Administración General del Estado es juez y parte en el procedimiento, provocando un cierto desequilibrio injustificado, «La repercusión en España de las sanciones impuestas al Estado...», op. cit., pág. 86.

29 En opinión del Consejo de Estado, expresada en su Informe sobre el proyecto de Real Decreto, la eventual responsabilidad derivada de la inactividad o defectuosa actividad del Estado podría ser asumida por éste por la vía de la responsabilidad concurrente contemplada en el art. 5. En esta misma línea, M. AzPitarte SÁnchez considera que el Real Decreto supone un avance en tanto que estima la existencia de responsabilidades concurrentes y prevé la distribución por mitades cuando no sea posible establecer el concreto grado de responsabilidad, «La distribución interna de la responsabilidad por incumplimiento del Derecho de la Unión...», op. cit., pág. 149. 
había provocado o contribuido a producir el incumplimiento de los compromisos asumidos por España ${ }^{30}$.

\section{A) El asunto Magefesa}

En el Asunto C-610/10 el Tribunal de Justicia resolvió un recurso por inejecución de sentencia presentado por la Comisión Europea ante la reiteración en el incumplimiento de la Decisión de la Comisión 91/1/ CEE, de 20 de diciembre de 1989, por la que se declaraban contrarias al Derecho de la Unión las ayudas concedidas por el Gobierno estatal y por diferentes Gobiernos autonómicos al Grupo Magefesa, con la consecuente orden de devolución de las mismas.

Así lo hicieron tanto el Gobierno estatal como los autonómicos, con la excepción de la Comunidad Autónoma del País Vasco, que no recuperó las ayudas dadas a la empresa Insa en forma de avales crediticios y subvenciones de intereses.

Aunque ésta quebró, sus actividades continuaron por medio de una filial, que asumió sus activos y el personal, así como la comercialización de los productos. Desaparecida también la filial, un conjunto de antiguos trabajadores crearon una sociedad limitada laboral a la que pasaron los activos, que también entró en liquidación. En consecuencia, pervivía la obligación de restituir las ayudas porque continuaba la actividad y se seguían utilizando los medios de Insa.

La Comunidad Autónoma del País Vasco, por ello, estaba obligada a personarse en el procedimiento concursal tramitado contra la sociedad limitada laboral y solicitar su inclusión en la lista de acreedores en relación

30 J unto con ello, debe tenerse presente también el Asunto C-278/01. La Sentencia del Tribunal de J usticia de la Unión Europea de 25 de noviembre de 2003 por la que se resolvió el mismo impuso a nuestro país la condena al pago de una multa coercitiva de 624.150 euros por cada punto porcentual de zonas de baño en aguas interiores que no cumplieran con los límites fijados en la Directiva reguladora de la materia, importe que debía satisfacerse a partir del momento en que se evaluara la calidad de las aguas (cada año). Aun cuando la competencia de gestión de la calidad de las aguas es de carácter autonómico y municipal (la limpieza en sí), ha de tenerse presente que el Reino de España podía haber solicitado a la Comisión un periodo transitorio de aplicación de la Directiva en el momento de adherirse a la Unión Europea y no lo hizo. Como consecuencia de ello, el Tribunal desestimó el argumento de la defensa de España en el sentido de que no contó con los 10 años de plazo de ejecución que la Directiva ofrecía y del que sí se beneficiaron el resto de Estados miembros pertenecientes con anterioridad a la Unión. Aunque finalmente el Reino de España no llegó a pagar la multa a la que había sido condenado por motivos de plazos de comprobación del nivel de contaminación, resulta evidente, pues, que esta omisión del Reino de España determinó una cuantía mayor de la multa coercitiva y, por ello, que, en el caso de que finalmente se hubiera procedido al pago de la misma, la repercusión por parte del Estado debería haber tomado en consideración esta parte de responsabilidad, que sólo a él era imputable. 
con las ayudas declaradas incompatibles con el mercado común (en total, 22.683.745 euros), lo que finalmente hizo y fue aceptado por el Juzgado de lo Mercantil competente, si bien en abril de 2012, una vez que se había producido la inejecución de la sentencia declarativa del incumplimiento.

Es muy ilustrativa la afirmación del Tribunal de Justicia en el marco de la Sentencia de 11 de diciembre de 2012, por la que resuelve este asunto, en respuesta a los argumentos del Reino de España relativos a que en los cálculos de la sanción a imponer debe tenerse en cuenta la capacidad de pago de la comunidad autónoma responsable y no la del conjunto del Estado (lo que supondría una minoración relevante de su cuantía): «la circunstancia de que un Estado miembro haya encomendado a sus regiones la función de llevar a cabo la recuperación de una ayuda ilegal e incompatible con el mercado común no puede tener incidencia alguna en la aplicación del artículo 260 TFUE. En efecto, si bien cada Estado miembro tiene libertad para repartir como considere oportuno las competencias del poder central y del poder regional en el orden interno, no es menos cierto que en virtud de ese mismo artículo dicho Estado miembro es el único responsable frente a la Unión del cumplimiento de las obligaciones que resultan del Derecho de la Unión». Se rechaza, pues, esta manifestación de la descentralización de la responsabilidad y se pone de manifiesto que el reparto interno de competencias no puede ser excusa ante un incumplimiento ni eximente de la imposición de una sanción, pero también que en la concreción del importe de la misma -como quedó reflejado con anterioridad al exponerse la fórmula matemática que sirve de referencia a tal fin- se tiene en cuenta el conjunto del Estado y no sólo la comunidad autónoma responsable.

J unto con ello, y a pesar de que la jurisprudencia constitucional tiene establecido que el Estado carece del poder de revisar la actuación de las comunidades autónomas contraria al Derecho de la Unión, es claro el deber de éste de advertir a la comunidad autónoma de la necesidad de corrección de su actuación como manifestación del principio de colaboración: «Tal advertencia a la comunidad autónoma resulta necesaria e imprescindible, no sólo como manifestación del principio de leal colaboración que está implícito en la Constitución y que es consustancial al Estado autonómico, sino también porque de no hacerlo estarían perjudicándose los intereses de los [...] españoles afectados» (STC 148/1998, de 2 de julio, F. J. 80).

En todo caso, el Acuerdo del Consejo de Ministros de 17 de octubre de 2014, por el que se resuelve el procedimiento de determinación y repercusión de responsabilidades por incumplimiento del Derecho de la Unión Europea relativo a la no ejecución de la Sentencia del Tribu- 
nal de J usticia de 2 de julio de 2002, no se planteó esta posibilidad y aprobó el acuerdo alcanzado con el Gobierno del País Vasco por el que éste procede al pago voluntario anticipado de la deuda por importe de 23.900.000 euros. Aunque en este procedimiento se efectuaron alegaciones por parte de la comunidad autónoma, tal y como se refleja en el texto del Acuerdo del Consejo de Ministros, el Gobierno autonómico abonó la deuda tras recibir los informes que habían sido solicitados por el órgano instructor a diferentes órganos estatales.

B) El Asunto de las vacaciones fiscales de las Diputaciones Forales vascas

En el Asunto C-184/11, resuel to por el Tribunal de Justicia en su Sentencia de 13 de mayo de 2014, se condena al Reino de España al pago de una suma a tanto alzado de 30 millones de euros por haber inejecutado la sentencia que reconocía el incumplimiento de varias Decisiones de la Comisión E uropea por las que se declaraba contrarias al Derecho de la Unión el régimen de ayudas a empresas establecido por las tres Diputaciones Forales vascas. E fectivamente, se entendió que una parte sustancial de las ayudas (en torno al 87\%, un total de $569.041 .135,75$ euros) no había sido recuperada.

EI Tribunal de Justicia lleva a cabo una afirmación que resulta de interés para el objeto de este análisis. Ante el argumento expuesto por el Reino de España de que el Tribunal debe precisar, respecto de cada una de las Decisiones incumplidas, qué cantidades no han sido recuperadas aún en la medida en que ello resulta imprescindible para poder repercutirlas posteriormente sobre el nivel territorial inferior responsable del incumplimiento, responde que «el reparto de competencias entre el poder central y el poder regional en el ámbito interno no afecta a la aplicación del artículo 260 TFUE, en la medida en que el Estado miembro de que se trate es el único responsable, frente a la Unión Europea, del cumplimiento de las obligaciones que resultan del Derecho de la Unión». Y, como consecuencia de ello, «la declaración de incumplimiento que realiza el Tribunal de J usticia en el marco del procedimiento regulado en el artículo 260 TFUE, apartado 2, no puede depender de las particularidades de la organización interna del Estado miembro de que se trate». En definitiva, correspondeal propio Gobierno estatal determinar el importe exacto de las cantidades que deben recuperarse.

Pero más interesante aún para la idea defendida en este trabajo en el sentido de que no sólo corresponde a las comunidades autónomas (o, 
en su caso, a los entes locales) el deber de asumir la parte de responsabilidad que les sea imputable ante un incumplimiento del Derecho de la Unión que derive en sanción es el hecho de que, ante el argumento por parte del Reino de España de que el procedimiento de recuperación de las ayudas era especialmente complejo en este caso y presentaba novedades que no se habían dado con anterioridad, lo cual debería tenerse en cuenta a la hora de minorar el importe de la suma a tanto alzado, el Tribunal lo descarta por considerar demostrado que las autoridades españolas no se pusieron en contacto con la Comisión antes de recibir el escrito de requerimiento con el fin de manifestarles tales problemas y sólo los expuso dos años después de que se dictara la sentencia declarativa del incumplimiento.

J unto con ello, el propio Tribunal tiene en cuenta a la hora de determinar el montante de la sanción que E spaña ya ha sido objeto de varias sentencias que declaran un incumplimiento por no haber recuperado de manera inmediata y efectiva ayudas declaradas ilegales e incompatibles con el mercado interior (asuntos en los que los autores materiales del incumplimiento objeto de la sentencia, Ias Diputaciones Forales vascas, nada tenían que ver), lo que le lleva a afirmar que «tal repetición de comportamientos políticos de un Estado miembro, en un sector específico de la acción de la Unión, puede constituir un indicador de que para prevenir efectivamente la repetición en el futuro de infracciones análogas del Derecho de la Unión es preciso adoptar una medida disuasoria, como la condena al pago de una suma a tanto alzado».

En definitiva, queda demostrado que tanto la elección de la medida a imponer como la cuantía de la misma responde en parte a comportamientos y omisiones del Estado central. En consecuencia, éste debería haber asumido la parte de responsabilidad que le corresponde, en aplicación de lo previsto en el art. 8 - ha contribuido a producir el incumplimiento al no expresar a la Comisión la complejidad de la recuperación de las ayudas, el montante de la sanción responde en parte a actuaciones del Estado central y su actuación ha influido en la determinación del mismo - y haber aplicado lo previsto en el art. 5 del Real Decreto 515/2013 para los casos de responsabilidad concurrente.

A pesar de ello, el Acuerdo del Consejo de Ministros de 17 de octubre de 2014, por el que se resuelve el procedimiento de determinación y repercusión de responsabilidades por incumplimiento del Derecho de la Unión Europea relativo a la no ejecución de la sentencia del Tribunal de J usticia de 14 de diciembre de 2006, no tuvo en cuenta estas circunstancias y aprobó el acuerdo alcanzado con las Diputaciones Forales vascas de puesta a disposición del Gobierno vasco de los 30 millones de euros 
de deuda. EI Gobierno Vasco renunció a formular al egaciones, actuando como simple intermediario del pago, y la cantidad se ingresó de manera anticipada a la finalización del procedimiento.

Como ha podido observarse, a pesar de que había argumentos en ambos asuntos para que las entidades repercutidas defendieran el deber del Estado de asumir parte de la responsabilidad derivada del incumplimiento y de que el Real Decreto 515/2013 que sirve de base para la adopción de los Acuerdos del Consejo de Ministros de determinación y repercusión de la responsabilidad presenta serias dudas de legalidad en relación con su aplicación respecto de las comunidades autónomas con régimen foral, los asuntos iniciados hasta el momento se han cerrado sin contestación alguna.

Se trata de una manifestación más del anacronismo reinante en relación con la ejecución del Derecho de la Unión Europea, continuidad del protagonismo del Estado central.

2. La posibilidad de repercutir frente al Estado las responsabilidades económicas sufridas por las comunidades autónomas

Una cuestión no planteada en el Real Decreto 505/2013-puesta de manifiesto por la doctrina y por las propias comunidades autónomas durante la fase de elaboración del $\mathrm{mismo}^{31}$ — es la relativa a la posibilidad de instar la repercusión a la inversa o ascendente, esto es, que las comunidades autónomas repercutan sobre el Estado las cantidades que hubieren podido dejar de recibir o han debido restituir como consecuencia de acciones u omisiones imputables a la Administración General del Estado.

La ausencia de mención específica de esta cuestión no significa que en nuestro ordenamiento jurídico no resulte posible hacer valer la repercusión ascendente.

Efectivamente, en los casos en los que las consecuencias económicas desfavorables afecten a las comunidades autónomas y se deriven de actuaciones $u$ omisiones en exclusiva imputables al Estado, los arts. 3 y 4 están redactados con la suficiente generalidad como para entender que son aplicables también a los mismos.

Como fue analizado en su momento, el concepto de incumplimiento incluye todo tipo de actuación u omisión contraria al Derecho de la

31 Quien ha planteado con mayor énfasis esta posibilidad en varios de sus trabajos ha sido M. Gómez PUENTE; por todos, «La repercusión interna de la responsabilidad por incumplimiento...», especialmente en págs. 26 y sS. Puede verse también SÁENZ DE SANTA M ARÍA, «Comunidades Autónomas y repercusión económica...», op. cit., pág. 56; y M. Cienfuegos Mateo, «La repercusión en España de las sanciones impuestas al Estado...», op. cit., pág. 89. 
Unión Europea, con independencia del nivel territorial del que provenga. Además, el término sanción también ha de ser entendido en sentido amplio. No abarca sólo las derivadas de los artículos 108, 126 o 260 TFUE que, por la lógica del funcionamiento del sistema, son satisfechas por el Estado central y deberán ser repercutidas con posterioridad en los casos de incumplimientos autonómicos. Incluye también «la minoración de las cuantías de las transferencias o fondos que a España le puedan corresponder del presupuesto de la Unión Europea o cualquier otro acto adoptado por una institución, órgano u organismo de la Unión Europea que implique responsabilidades financieras para el Estado» $y$, sobre todo, en general, «la merma de cualquier cantidad que le hubiera sido reconocida». En el concepto Estado debe entenderse incluido tanto el Estado central como las comunidades autónomas. En consecuencia, puede entenderse dentro del ámbito de aplicación del Real Decreto el supuesto de perjuicio patrimonial autonómico derivado de incumplimientos estatales.

Es este detrimento patrimonial el que habilita la entrada en juego del mecanismo de repercusión. De este modo, el art. 4, a la hora de determinar la responsabilidad por el incumplimiento del Derecho de la Unión Europea, señala que «se repercutirán las responsabilidades derivadas de sanciones ejecutivas por incumplimiento del Derecho de la Unión Europea a aquellas Administraciones Públicas [...] que sean competentes de conformidad con el ordenamiento jurídico español y que realicen una acción u omisión que dé lugar a un incumplimiento». Por tanto, simplemente está indicando que debe pagar el montante de la sanción el autor material de la misma, sea quien sea. Podría pensarse que, dado que quien ha de pagar la sanción es el Reino de España, cuando sea el Estado central el responsable del incumplimiento, no cabrá aplicar la repercusión, de modo tal que el mecanismo está pensado y es útil sólo para los casos de incumplimiento autonómico y pago estatal. Sin embargo, puede darse la circunstancia de que se produzcan sanciones, correcciones financieras 0 , en general, merma de cantidades que afectan a las comunidades autónomas cuando el incumplidor es el Estado central. En estos casos también deberá iniciarse por parte de la Secretaría General de Coordinación Autonómica y Local del Ministerio de Hacienda y Administraciones Públicas - o el órgano competente en materia de fondos europeos- el procedimiento de repercusión para que el Consejo de Ministros pueda determinar el sujeto incumplidor, los criterios de imputación, el importe de la deuda y los mecanismos para que aquél la haga efectiva a las comunidades autónomas afectadas. También resultaría de aplicación la posibilidad de reconocimiento - autorreconocimiento, en 
realidad - de la responsabilidad del art. 15 y proceder al pago voluntario. Tan sólo el art. 17, que regula los mecanismos de repercusión de responsabilidades, no resultaría de aplicación, pues está pensado para que sea el Estado central quien compense, deduzca o retenga las cantidades adeudadas al sujeto responsable.

En todo caso, puede afirmarse la existencia de cauce procedimental para que el Estado central reconozca su deuda con las comunidades autónomas por incumplimientos del Derecho de la Unión a él imputables y proceda al pago de la misma.

3. Una vía intermedia: el establecimiento de un modelo de responsabilidades fijas

Algunos autores, sobre la base de la experiencia de países de nuestro entorno, han señalado la posibilidad de establecer un modelo de responsabilidades fijas entre Estado y comunidades autónomas para los supuestos de sanción del incumplimiento del Derecho de la Unión Europea, con independencia del grado de intervención material de cada uno de ellos en el caso concreto ${ }^{32}$. Late tras este planteamiento una cierta desconfianza hacia el mecanismo de repercusión de la responsabilidad, considerando más eficaz la fijación de una escala de responsabilidad sobre la base del reparto de competencias general previsto en nuestro sistema constitucional ${ }^{33}$.

32 Sin duda alguna, quien se ha mostrado partidario de esta posibilidad con más insistencia es M. AzPITARTE SÁNCHEZ, «La distribución interna de la responsabilidad por incumplimiento del Derecho de la Unión», en X. Arzoz Santisteban (dir.) (2013), Transposición de directivas y autogobierno. EI desarrollo normativo del Derecho de la Unión Europea en el Estado autonómico, Institut d'Estudis Autonòmics, Barcelona, págs. 147 y ss. Su tesis parte de la distinción entre funciones: no es lo mismo transponer que ejecutar, es decir, desarrollar normativamente el Derecho de la Unión (donde rige principalmente el principio de atribución) que adoptar medidas ejecutivas de cumplimiento (donde rige el principio de cooperación). En su opinión, ello tiene consecuencias sobre el deber de cumplimiento por parte de los Estados miembros, de tal modo que mientras que la transposición exige la adaptación del marco normativo, la ejecución busca el reconocimiento, modificación o supresión de situaciones jurídicas específicas. Teniendo en cuenta que el procedimiento sustanciado ante el Tribunal de Justicia permitirá saber quién ha de adoptar las medidas necesarias para acatar la sentencia declarativa del incumplimiento, sostiene que «en la reparación reside la imputación» (pág. 162). Ello conduce al autor a mantener un sistema de distribución de responsabilidad previamente determinado con porcentajes asignados en función del tipo de actuación exigida. Estas ideas ya habían sido adelantadas en un trabajo anterior, previamente citado: «¿Quién ha de pagar el incumplimiento del Derecho de la Unión, el Estado o las comunidades autónomas? A propósito de algunos aspectos de interés del Informe del Consejo de Estado de 15 de diciembre de 2010», Revista d'Estudis Autonòmics i Federals, 15, 2012, págs. 91 y ss.

33 íbíd., pág. 162. En opinión de este autor, si el incumplimiento se produce en el ámbito de la distribución competencial bases-desarrollo, podría fijarse un $60 \%$ de responsabilidad estatal 
Un sistema de esta naturaleza permite ofrecer seguridad jurídica y puede tener un cierto efecto preventivo, particularmente para el Estado, a la hora de optar por instrumentos de coordinación para evitar eventuales incumplimientos del Derecho de la Unión, consciente de que, incluso aunque nada tenga que ver con los mismos, le corresponderá asumir un tanto de responsabilidad. J unto con ello, en el caso de repercusión de multas coercitivas o sumas a tanto alzado impuestas en aplicación del art. 260 TFUE, haría posible que el Estado asumiera la parte de las mismas que viene predeterminada como consecuencia del método de cálculo empleado por la Comisión.

Como contrapartida, objetiviza en exceso el reparto de responsabilidades, en detrimento de la asunción de las consecuencias económicas derivadas de los incumplimientos por parte de sus verdaderos autores, rompiendo la lógica competencia-responsabilidad.

A la hora de pronunciarse sobre esta cuestión, debe tenerse presente que no es lo mismo desarrollar normativamente el Derecho de la Unión -lo que ocurre principalmente en el caso de transposición de Directivas- que ejecutar el Derecho de la Unión. En este último supuesto, es evidente que en la mayor parte de los casos resultará más sencillo determinar quién es el autor material del incumplimiento, puesto que no entran en juego las complejidades del reparto competencial en relación con la potestad legislativa. Es en el desarrollo normativo donde esta escala de responsabilidad puede tener mayor virtualidad, especialmente en los casos complejos.

Sin embargo, tal y como ha sido desarrollado lo previsto en la LOEPSF por parte del Real Decreto 515/2013 —en el sentido de que el Consejo de Ministros determinará en los casos de actuación u omisión conjunta el grado de responsabilidad que corresponde a cada una de las Administraciones implicadas y, cuando no sea posible, la distribución se llevará a cabo por partes iguales- un sistema de porcentajes fijos predeterminados no mejoraría la situación.

Además, se ha de tener en cuenta que en los sistemas donde se ha introducido este instrumento de distribución de la responsabilidad (especialmente, Alemania), la propia Constitución nacional prevé poderes de intervención más amplios para el Estado central sobre los entes descentralizados o, en palabras del Consejo de Estado ${ }^{34}$, en todos ellos exis-

y un $40 \%$ de responsabilidad autonómica. Si, por el contrario, afecta al reparto legislaciónejecución, el porcentaje sería 80-20. En el caso de que sean varias las comunidades autónomas afectadas, podría establecerse una regla de reparto entre ellas que tenga como base de referencia su PIB o cualquier otro indicador de riqueza.

34 Véase el Informe de 15 de diciembre de 2010, págs. 174 y ss. Paradójicamente, sin embargo, al menos en relación con la transposición de Directivas, se ha constatado que el Estado 
te una regulación constitucional de los mecanismos para la garantía del cumplimiento de las obligaciones europeas, que incluye no sólo poderes de sustitución de aquél frente a éstos, sino, además, el poder de repercusión de las consecuencias económicas.

Un sistema de responsabilidades fijas que no lleva aparejado una regulación de amplios poderes de intervención del Estado central sobre materias de competencia autonómica sería incongruente.

\section{Conclusiones}

Resulta evidente en nuestro ordenamiento jurídico el hecho de que, hasta el momento, tanto el legislador como el Ejecutivo estatales han centrado sus esfuerzos más en abrir vías para canalizar la repercusión de la responsabilidad derivada del incumplimiento del Derecho de la Unión Europea que en explorar mecanismos para evitar incurrir en esa responsabilidad. Detrás de esta realidad parece latir el rechazo al aumento de los poderes estatales en relación con la prevención de los incumplimientos, y no precisamente por respeto al principio de autonomía y a las competencias autonómicas y locales, sino más bien porque de ello se derivaría un mayor grado de responsabilidad del Estado en los eventuales incumplimientos. Dicho sencillamente, a mayores poderes de intervención, menor posibilidad de repercusión de las consecuencias derivadas del incumplimiento del Derecho de la Unión 35 .

Con independencia de ello, debe entenderse que la vía de la repercusión resulta más garantista para el principio de autonomía constitucionalmente reconocido a las comunidades autónomas que el fortalecimiento de los poderes del Estado central en la ejecución del Derecho de la Unión para prevenir los incumplimientos. A través de ella, si se aplica respetando el principio de equidad y partiendo de una declaración objetiva de la responsabilidad imputable, en la parte que les corresponda, a los sujetos que han provocado el incumplimiento sancionado - incluyendo al propio Estado central-, se consigue normalizar el sistema de ejecución desde la perspectiva de los incumplimientos.

ha asumido un papel protagonista en detrimento de las comunidades autónomas, de tal modo que éstas han delegado en él la labor de primera transposición, con independencia de que la competencia les corresponda a ellas, sin que ello se vea reflejado en el mecanismo de repercusión introducido en nuestro ordenamiento jurídico.

35 Así lo afirma el Consejo de Estado en su Informe sobre el Proyecto de Real Decreto por el que se regulan los criterios y el procedimiento para determinar y repercutir las responsabilidades por incumplimiento del Derecho de la Unión Europea. 
Efectivamente, desde la óptica de la Unión Europea, la sanción o la corrección financiera determinada por la institución competente para ello pone fin a un incumplimiento del Derecho de la Unión. Constituyen, en definitiva, la garantía última del sistema: el Estado infractor paga por su incumplimiento. Desde la óptica nacional, sin embargo, en el caso de los Estados descentralizados, el pago a la Unión Europea no siempre permite dar por cerrado el incumplimiento. Así ocurre en los casos en los que la acción u omisión que ha derivado en sanción por incumplimiento sea imputable a una o varias comunidades autónomas, en todo o parte, en los que resulta imprescindible la repercusión de la responsabilidad. Pretender reaccionar frente a estas situaciones potenciando los poderes del Estado central, principalmente teniendo en cuenta el número de casos en los que concurre el supuesto de hecho habilitante de la repercusión, no es la solución más proporcional ni más razonable. Ha de tenerse en cuenta, además, que gran parte de las reflexiones a nivel doctrinal -también las del Consejo de Estado- han sido formuladas en relación con la falta de transposición de Directivas como motivo de incumplimiento y no tanto sobre los incumplimientos ejecutivos. En análisis de los supuestos en los que se ha aplicado el mecanismo de repercusión pone de manifiesto que es precisamente este segundo tipo de incumplimientos el más generalizado (hasta el momento no se ha producido ninguna sanción por falta de transposición de Directivas). Ello ha de ser tomado en consideración a la hora de realizar cualquier planteamiento sobre el reforzamiento de los poderes de intervención del Estado.

La falta de reconocimiento en nuestra Constitución de la integración de España, como Estado descentralizado, en la Unión Europea tiene consecuencias negativas para los diferentes niveles territoriales y genera disfunciones. Junto al hecho de que el cumplimiento del Derecho de la Unión Europea ha servido al Estado para ampliar su ámbito competencial cuando actúa en ejecución del mismo ${ }^{36}$, éste está obligado a garantizar su cumplimento sin contar con instrumentos de intervención sobre las comunidades autónomas, pudiéndose limitar a repercutir las responsabilidades económicas derivadas del incumplimiento.

36 En el capítulo de conclusiones de la obra Transposición de directivas y autogobierno. El desarrollo normativo del Derecho dela Unión Europea en el Estado autonómico, ya citada, (titulado «La transposición de Directivas en el Estado autonómico: diagnóstico y perspectivas de futuro»), Xavier Arzoz destaca que un análisis de la forma en que se transponen las Directivas en nuestro país pone de manifiesto cómo se ha producido un desplazamiento competencial en favor del Estado, con vaciamiento de las capacidades legislativas de las comunidades autónomas y reconversión de títulos competenciales autonómicos exclusivos en compartidos e, incluso, concurrentes (pág. 499). 
No puede negarse la competencia del Estado para regular mecanismos procedimentales de repercusión de la responsabilidad que ha de asumir ante las instituciones europeas por el hecho de ser el único actor válido a nivel internacional -entre otras razones, porque así lo viene reiterando el Tribunal Constitucional con insistencia-; sin embargo, resulta preciso normalizar las relaciones de cooperación entre Estado y comunidades autónomas a la hora de determinar el tanto de responsabilidad que corresponde a cada uno en los incumplimientos y, por tanto, a la hora de repercutir las sanciones. Ello debería tener su extensión en relación con la cooperación en la ejecución del Derecho de la Unión como mecanismo para evitar los incumplimientos ${ }^{37}$.

Puede afirmarse que el Real Decreto 515/2013 se ha mostrado útil en sus primeras aplicaciones, permitiendo el traslado dela sanción satisfecha por el Estado a las comunidades autónomas responsables del incumplimiento. Sin embargo, ello no impide afirmar que necesita mejoras. Principalmente, en lo relativo al reconocimiento por parte de la Administración central de su parte de responsabilidad en incumplimientos autonómicos. A tal fin no es necesaria una reforma - aunque resultaría conveniente, sin duda-, sino que basta con una lectura amplia de sus preceptos, de tal modo que en ellos quepan tanto la responsabilidad concurrente como la repercusión ascendente o a la inversa. Además, ha de tenerse en cuenta que las comunidades autónomas también son Estado. A ellas les incumbe igualmente la obligación de cumplir el Derecho de la Unión y de garantizar el cumplimiento. Por esta razón, su participación en el mecanismo de repercusión no debería limitarse a un simple trámite de audiencia para expresar su opinión respecto del acuerdo de iniciación del procedimiento y, en concreto, la determinación de los hechos, de los criterios de imputación y del responsable del incumplimiento.

Se trata, en última instancia, de compensar la pérdida de poder de las comunidades autónomas institucionalizada en nuestro sistema jurídico a través de la asunción por el Estado central de la responsabilidad que le corresponde en coherencia con el poder que real mente ejerce. De no hacerse así, la repercusión de la responsabilidad por incumplimiento del Derecho de la Unión Europea constituirá una nueva anomalía del Estado autonómico en el contexto europeo.

37 En este sentido, X. Arzoz plantea como propuesta la creación de un «grupo de alto nivel de la adaptación del Derecho de la Unión», integrado por representantes del Estado y de las comunidades autónomas, que conecte ejecución con elaboración del Derecho de la Unión a nivel interno y que permita el intercambio de información y la coordinación entre los niveles territoriales de Gobierno, ibíd., págs. 555 y ss. 